\title{
Recursos tecnológicos para la integración de la gamificación en el aula
}

\author{
Hugo Trejo González \\ Maestro de Tecnologías para el Aprendizaje de la \\ Universidad de Guadalajara (México) \\ hugo.trejo@outlook.com
}

\section{Extracto}

El objetivo principal de este artículo consiste en esclarecer la disposición actual de herramientas tecnológicas aplicables a la perspectiva didáctica de gamificación. Para ello, hemos indagado en un motor de búsqueda de uso común en internet con la finalidad de obtener información sobre recursos tecnológicos para construir un referente que permita identificar las funciones generales, los objetivos y el impacto en las mecánicas, en las dinámicas y en los componentes de la perspectiva educativa aludida. Los resultados han permitido obtener información sobre 23 recursos tecnológicos relacionados con el ámbito de estudio. Además, con los resultados hemos analizado tres herramientas con el objetivo de contribuir a la comprensión de sus funciones para ayudar en su posible adaptación a los ambientes de aprendizaje lúdicos.

Palabras clave: gamificación; innovación educativa; recursos de internet; técnicas de motivación; motivación intrínseca. 


\title{
Technological resources for the integration of gamification in the classroom
}

\author{
Hugo Trejo González
}

\begin{abstract}
The main objective of this article is to elucidate the current disposition of the technological tools applied to the didactic perspective of gamification. For this, we have conducted a research on the internet through a search engine commonly used to obtain information on technological resources to build a reference in order to identify the general functions, objectives and impact on the mechanical areas, dynamics and components of the aforementioned educational perspective. The results have allowed us to obtain information on twenty-three technological resources related to the field in question. In addition, with the results we have carried out the analysis of three tools to elucidate their main functions and their possible adaptation in ludic learning environments.
\end{abstract}

Keywords: gamification; educational innovation; internet resources; motivation techniques; intrinsic motivation.

Citation: Trejo González, H. (2019). Technological resources for the integration of gamification in the classroom. Tecnología, Ciencia y Educación, 13, 75-117. 


\section{Sumario}

1. Introducción

2. Gamificación en el aula

3. Método y resultados

4. Análisis

\subsection{Pear Deck}

4.1.1. Descripción general

4.1.2. Usos en gamificación

4.1.3. Limitaciones e inconvenientes

4.1.4. Evaluación de las características de usabilidad web y gamificación

4.2. Classcraft

4.2.1. Descripción general

4.2.2. Usos en gamificación

4.2.3. Limitaciones e inconvenientes

4.2.4. Evaluación de las características de usabilidad web y gamificación

4.3. Quizizz

4.3.1. Descripción general

4.3.2. Usos en gamificación

4.3.3. Limitaciones e inconvenientes

4.3.4. Evaluación de las características de usabilidad web y gamificación

5. Conclusiones

Referencias bibliográficas 


\section{Introducción}

En la actualidad, los profesores se enfrentan constantemente a retos tecnológicos y metodológicos que los obligan a transformar sus hábitos de enseñanza. Continuamente, los ambientes educativos tienden a adecuarse a las nuevas tendencias de enseñanza, a las necesidades estudiantiles y a los cambios que impactan en la manera de comunicar, aprender e interactuar con la información. En este marco, la motivación del estudiante juega un papel fundamental en el éxito de los procesos educativos. Como dice Contreras (2016), «la motivación es necesaria para garantizar el aprendizaje y para evaluar un programa educativo, pues cuando un estudiante se encuentra motivado, la efectividad de la actividad aumenta» (p. 28). Con el propósito de atender esta necesidad, se plantean nuevas formas de concebir los entornos buscando transformar el aprendizaje de los estudiantes mediante la creación de ambientes que promuevan una mejor aceptación didáctica. Este es el caso de la metodología "gamificación» (en inglés, gamification), perspectiva en la que la motivación representa un aspecto importante. Esta tendencia didáctica se centra en la mejora de la dinámica grupal mediante la integración de características de los videojuegos en los procesos de enseñanza en el aula. Moreno, Leiva y Matas (2016) la definen como «el empleo de mecánicas de juego en entornos y aplicaciones no lúdicas con el fin de potenciar la motivación, la concentración, el esfuerzo, la fidelización y otros valores positivos comunes a todos los juegos» (p. 19).

Por otra parte, el aspecto lúdico, junto con la integración de las tecnologías de la información y la comunicación (TIC), permiten diversificar actividades que den como resultado un ambiente de aprendizaje atractivo para los estudiantes. Las posibilidades educativas de los nuevos inventos plantean diferentes alternativas de apoyo a la gamificación mediante el uso de aplicaciones para

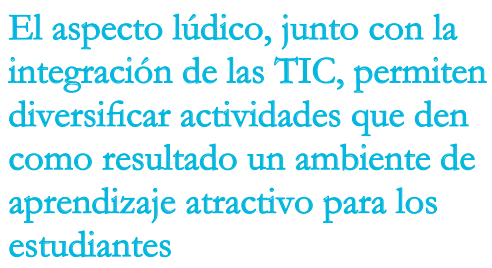
integración de las TIC, permiten diversificar actividades que den como resultado un ambiente de aprendizaje atractivo para los estudiantes facilitar las actividades lúdicas en el aula. No obstante, aunque la gama de programas disponibles que podrían contribuir a la integración de la gamificación es extensa, la dificultad se presenta en el momento de decidir qué elegir y cómo aplicarlo en los diferentes contextos (Pascual-Seva et al., 2015). Con el objetivo de buscar una respuesta a estas cuestiones y esclarecer las posibilidades de ludificación en el aula, este estudio se enfoca en consolidar el conocimiento actual de la disponibilidad tecnológica para apoyar las técnicas de ludificación en la clase. Mediante la búsqueda en medios digitales, hemos obtenido información sobre la situación actual en la materia con la finalidad de crear un referente descriptivo de las capacidades, de los usos y de los alcances de algunas herramientas aplicables a la gamificación en contextos educativos. 
Para dar cuenta del trabajo realizado, este estudio se organiza de la siguiente manera: en primer lugar, presentaremos los fundamentos teóricos, buscando esclarecer los conceptos implicados en la cuestión; en segundo lugar, expondremos el método utilizado para recabar la información, así como los resultados obtenidos y la delimitación del corpus de herramientas que se van a analizar; en tercer lugar, presentaremos el análisis de las características de tres aplicaciones con el objetivo de acotar la información, esclarecer sus funciones lúdicas y evaluar su funcionamiento general; y, finalmente, presentaremos las conclusiones del estudio.

\section{Gamificación en el aula}

Aunque no existe una definición absoluta de gamificación (Lozada-Ávila y Betancur-Gómez, 2017), para algunos autores, como Oliva (2016), este concepto representa «una dinámica que aglomera componentes que, en forma recurrente, vemos en juegos de vídeo, en los que se pretende como fin último [...] la integración de una serie de dinámicas que permiten aumentar la participación de los estudiantes en sesiones educativas motivantes y útilmente entretenidas» (p. 32).

Por su parte, Foncubierta y Rodríguez (2014) insisten en que gamificar no solo implica lo lúdico, pues las actividades de clase, aunque son modificadas para resultar atractivas, disponen de un objetivo pedagógico que sobrepasa el juego. Además, «con el uso de la gamificación es posible incluir actividades como el estudio formal, la observación, la evaluación, la reflexión, la práctica, la gestión y el perfeccionamiento de habilidades» (Contreras, 2017, p. 13).

A diferencia del aprendizaje basado en juegos, en el que se integran actividades lúdicas, en su mayoría con mecánicas ya preestablecidas, la gamificación implica una transposición de las clases a un entorno de tipo videojuego mediante la asignación de premios, puntos, y un avance de la progresión a través de niveles (Villalustre y Del Moral, 2015).

Como indica Parente (2016), no se debe confundir la gamificación con juegos o videojuegos, ya que es un proceso más complejo y estratégico, basado en fundamentos no solamente del videojuego, sino también en la neuropsicología, y que debe ser realizado por especialistas adecuados de varios ámbitos.

Por otro lado, aunque la metodología de gamificación se basa en peculiaridades de los juegos en clase, esta dispone de características que se integran y repiten continuamente, lo que permite que los implicados estén más interesados por los contenidos durante el desarrollo de las actividades lúdicas (Díaz y Troyano, 2013).

En relación con los videojuegos, Aznar-Díaz, Raso-Sánchez, Hinojo-Lucena y RomeroDíaz (2017) acotan tres supuestos que deberían ser considerados en la construcción de entornos ludificados: 
- Orientación a objetivos.

- Reconocimiento.

- Progreso.

El primer supuesto indica que el participante deberá realizar una serie de actividades lúdicas basadas en objetivos que supondrán la superación de retos y etapas con el fin de ganar. El reconocimiento considera esclarecer los logros de estas actividades mediante la presentación de clasificaciones y el otorgamiento de recompensas. El tercer supuesto implica que la información sobre el avance y el camino por recorrer esté siempre disponible para su consulta. En este punto se requiere que el docente reoriente y ofrezca sugerencias a sus estudiantes.

Resulta indispensable que, en el programa en el que se pretende implementar este enfoque, se considere «la aplicación de los elementos estructurales de los juegos, la necesidad de comprometer a quienes participan de estas dinámicas y el planteamiento de una experiencia derivada de la interacción en un entorno que funciona como interfaz para alcanzar un objetivo y no solo como un medio de entretenimiento» (Gallego y Ágredo, 2016, p. 64).

En lo que se refiere a la motivación, esta juega un papel importante en el éxito de la metodología en cuestión. Según Sánchez-Rivas y Pareja-Prieto (2015), se requiere que dentro del entorno ludificado predominen actividades motivadoras intrínsecas. El estudiante deberá desarrollar un interés innato que lo mantendrá activo durante los proyectos propuestos. Para lograr la iniciativa se necesita trabajar en el refuerzo de las pautas que desarrollarán la disposición individual para realizar las actividades sin la motivación extrínseca (por parte del profesor).

Para lograr los supuestos comentados anteriormente, Werbach (2012) (citado en OrtizColón, Jordán y Agredal, 2018) sugiere el desarrollo integral de tres fundamentos básicos:

- Dinámicas.

- Mecánicas.

- Componentes.

El primero supone la integración del contexto y la estructura; por ejemplo, la narración, la interacción y las emociones. El segundo implica la incorporación de las pautas que dirigirán el proceso lúdico: retos, recompensas, competencias, entre otros. Finalmente, los componentes se refieren a los elementos físicos o virtuales que evidenciarán el avance y la disposición de niveles: clasificaciones, premios, puntos, etc.

Los beneficios de la gamificación en los procesos educativos son diversos. Considerando los resultados de Corchuelo-Rodríguez (2018), esta perspectiva aplicada en el aula se distingue por un aumento significativo de la motivación y de la participación de los estudiantes en las actividades educativas. Por su parte, Carrión (2018) ha logrado observar 
durante su práctica con las tecnologías de la información y la comunicación (TIC) aplicadas a la gamificación mejoras en el desarrollo de las competencias de los estudiantes, quienes han incrementado su motivación, su comunicación y su sentido crítico gracias a propuestas innovadoras y significativas de aprendizaje. En efecto, Oliva (2016) afirma que «el objetivo general de la gamificación como estrategia metodológica de la mejora docente en el aula universitaria persigue incidir en forma positiva a que el estudiantado pueda lograr el cumplimiento a cabalidad de objetivos específicos de aprendizaje» (p. 30). Además, lo educativo y lo lúdico tienen elementos en común.

El juego requiere además que el jugador tenga un cierto estado de ánimo -una predisposición a jugar- y que siga unas reglas, exactamente igual que pasa en la educación, al igual que con cualquier programa educativo, proceso o actividad (Contreras, 2016, p. 32).

Por otra parte, aunque esta metodología podría ser considerada como nueva y quizás aún se necesita un mayor número de estudios que determinen de manera unificada su impacto en la docencia (Hamari, Koivisto y Sarsa, 2014), en los últimos años se ha podido observar un incremento de las experiencias y de los estudios con esta metodología (Caponetto, Earp y Ott, 2014).

Finalmente, en lo que se refiere a las tecnologías digitales, Pomata y Díaz (2017) estiman que la manera más fácil de desarrollar un entorno gamificado es mediante el uso de las TIC y, a su vez, «una forma de adentrarnos en el mundo TIC dentro del centro escolar es la gamificación en el aula» (Sierra y Juste, 2018). De igual forma, las nuevas tecnologías aplicadas a la educación facilitan los procesos de gestión y de creación de materiales didácticos. Mediante la disposición abierta de programas, herramientas y soportes multimedia, el profesor puede hacer uso de diferentes recursos sin tener que formarse en aspectos técnicos de diseño con el fin de incorporar materiales interesantes en la clase.

Las TIC son las que facilitan de manera creativa y lúdica la interdisciplinariedad o transdisciplinariedad del currículo vigente y creemos que las buenas prácticas están ligadas, en primer lugar, a este carácter interdisciplinario que se facilita con las TIC (Jerí, 2008, p. 43).

Ante las posibilidades y el impacto didáctico con la integración de las TIC, resultaría interesante rescatar la perspectiva de Martín (2017), según la cual, además de considerar indispensable contar con los recursos tecnológicos para la implementación metodológica de una nueva perspectiva docente, es necesario que exista una reflexión profunda de los componentes que integran la nueva realidad
Es necesario que exista una reflexión profunda de los componentes que integran la nueva realidad educativa, haciendo énfasis especialmente en el estudio consciente de los objetivos, de los métodos y de los contenidos en función de la práctica docente 
educativa, haciendo énfasis especialmente en el estudio consciente de los objetivos, de los métodos y de los contenidos en función de la práctica docente.

\section{Método y resultados}

Con el fin de contribuir a la integración de medios tecnológicos para la implementación de la gamificación en el aula, esta investigación se basa en el estudio de algunas herramientas digitales disponibles en el año 2019. Con el objetivo de obtener información sobre aplicaciones tecnológicas que ayuden a los profesores a integrar la gamificación en el aula, este trabajo ha sido estructurado en cuatro partes principales:

- Recuperación y estudio de disponibilidad de herramientas.

- Organización de datos en función de posibilidades de gamificación.

- Selección de aplicaciones.

- Análisis individual.

En la primera etapa, con el objetivo de obtener datos sobre la disponibilidad tecnológica en la materia de interés, se han realizado indagaciones en exploradores web (Microsoft Edge, Firefox y Chrome) y en diversos motores de búsqueda disponibles en internet (Bing, Google y Yahoo!). En primera instancia, al observar que la cantidad de sitios y de referencias a aplicaciones en cuestión es numerosa, se ha decidido limitar la indagación a un solo buscador con la finalidad de contar con un mejor enfoque para el objetivo de esta investigación; de lo contrario, el estudio se centraría más en la disponibilidad tecnológica actual y no en las posibilidades didácticas de las herramientas para la integración de la gamificación en el aula. Por esta razón, la indagación se ha limitado a uno de los buscadores más utilizados en la actualidad: Google. Como es sabido, la ludificación es una perspectiva que está en auge; bastaría con buscar en el motor aludido el término en cuestión o estudiar los resultados de otros investigadores del ámbito, por ejemplo, Willging et al. (2017). No es de nuestro interés ofrecer una descripción exhaustiva de la disposición total de herramientas tecnológicas aplicables a la gamificación, sino acotar la información, ofrecer una clasificación de instrumentos y presentar la descripción de algunos de ellos a fin de mostrar sus posibilidades didácticas en función de las dinámicas, de las mecánicas y de los componentes implicados en la metodología referida (Werbach [2012], citado en Ortiz-Colón et al., 2018).

Dicho esto, en la etapa de recolección de datos, se ha procedido a la búsqueda de aplicaciones digitales para la gamificación en clase utilizando en una sola búsqueda los términos «herramientas para la gamificación» en el motor de Google. Cabe señalar que, para facilitar la obtención de información para futuras referencias a este trabajo, se ha decidido hacer uso solamente de los datos obtenidos en los cinco primeros sitios web que han apa- 
recido en nuestra página de búsqueda en el motor anteriormente mencionado. Convendría subrayar que, igual que ocurría en el caso anterior, el hecho de revisar toda la página de búsquedas implicaría un trabajo distinto al que se plantea en este estudio, que conllevaría obtener resultados significativos sobre la cantidad y no sobre la aplicación en clase de cada instrumento. Consideramos más pertinente para este trabajo estudiar los sitios web más populares, siendo estos aquellos que aparecen normalmente en primer lugar en las listas de resultados de la plataforma mencionada.

Por otra parte, los sitios encontrados han sido utilizados solamente para obtener los nombres de las herramientas tecnológicas aplicables a la gamificación. No se ha realizado un estudio profundo de la información presentada en cada sitio web. La investigación solo se ha decantado por la obtención de nombres para su posterior estudio en las páginas oficiales de cada herramienta. De esta actividad nos resulta indispensable resaltar la facilidad con la que se obtiene
Nos resulta indispensable resaltar la facilidad con la que se obtiene información sobre medios digitales que favorecen los procesos de gamificación. Conviene destacar que este ejercicio resultaría beneficioso para los profesores interesados en este campo información sobre medios digitales que favorecen los procesos de gamificación. Conviene destacar que este ejercicio resultaría beneficioso para los profesores interesados en este campo. En el cuatro 1 se muestra la información que se ha obtenido tomando como base los resultados arrojados en los primeros cinco sitios de la indagación realizada en el motor de búsqueda de Google.

\section{Cuadro 1. Resultados de la indagación en el buscador Google}

Sitio web 1:

$<$ https://www.educaciontrespunto cero.com/recursos/herramientas-ga mificacion-educacion/33094.html>

Brainscape
Knowre
Cerebriti
Minecraft: Education Edition
Pear Deck
Kahoot!
Edmodo
Classcraft
CodeCombat
ClassDojo

ChemCaper

Quizlet

Toovari

The World Peace Game

Play Brighter

Quizizz

Monster Kit

Trivinet

Arcademics

Genially 


\begin{tabular}{|c|c|c|}
\hline Sitios web & \multicolumn{2}{|c|}{ Herramientas tecnológicas encontradas } \\
\hline$\triangleright$ & & \\
\hline $\begin{array}{l}\text { Sitio web 2: } \\
\text { <http://www.educacionyculturaaz. } \\
\text { com/noticias/10-herramientas-de- } \\
\text { gamificacion-para-el-aula> }\end{array}$ & $\begin{array}{l}\text { Brainscape } \\
\text { Knowre } \\
\text { Cerebriti } \\
\text { Minecraft: Education Edition } \\
\text { Pear Deck }\end{array}$ & $\begin{array}{l}\text { Kahoot! } \\
\text { Edmodo } \\
\text { Classcraft } \\
\text { CodeCombat } \\
\text { ClassDojo }\end{array}$ \\
\hline $\begin{array}{l}\text { Sitio web 3: } \\
<\text { https://www.evirtualplus.com/herra } \\
\text { mientas-de-gamificacion-para-univer } \\
\text { sitarios/> }\end{array}$ & $\begin{array}{l}\text { FlipQuiz } \\
\text { Quizizz } \\
\text { Socrative } \\
\text { Kahoot! } \\
\text { uLearn Play }\end{array}$ & \\
\hline $\begin{array}{l}\text { Sitio web 4: } \\
\text { <http://jaimegrau.es/gamificacion-en- } \\
\text { el-aula-6-herramientas-gratuitas-que } \\
\text {-ya-deberias-conocer/> }\end{array}$ & $\begin{array}{l}\text { ClassDojo } \\
\text { Kahoot! } \\
\text { Quizizz }\end{array}$ & $\begin{array}{l}\text { Toovari } \\
\text { Classcraft } \\
\text { Playbrighter }\end{array}$ \\
\hline $\begin{array}{l}\text { Sitio web 5: } \\
\text { <http://noticias.universia.cl/educacion/ } \\
\text { noticia/2018/05/10/1159765/5-herra } \\
\text { mientas-aplicar-gamificacion-clase. } \\
\text { html> }\end{array}$ & $\begin{array}{l}\text { Cerebriti } \\
\text { Brainscape } \\
\text { Edmodo } \\
\text { Kahoot! } \\
\text { Classcraft }\end{array}$ & \\
\hline
\end{tabular}

Fuente: elaboración propia.

Como se puede apreciar en el cuadro 1, esta indagación nos ha permitido obtener información sobre la existencia de 23 aplicaciones distintas relacionadas con el término "gamificación". Así, en el primer sitio web se han conseguido 20 nombres; en el segundo sitio, 10; en el tercer sitio, 5; en el cuarto sitio, 6; y en el quinto sitio, 5. En suma, se ha conseguido información de 46 referencias de herramientas, pero muchas de ellas se repiten en los diferentes sitios web, por lo que solamente se obtuvo un total de 23 herramientas distintas. La investigación podría haberse delimitado utilizando conceptos relacionados con la educación; sin embargo, se ha querido ampliar el espectro de búsqueda para localizar más herramientas que sean aplicables en contextos educativos, aunque estas no hayan sido concebidas para fines didácticos. Reiteramos que no se ha tomado en consideración ninguna de las descripciones de las herramientas mencionadas en ninguno de los cinco sitios web de nuestra indagación. Estos se han utilizado solamente para obtener los nombres de los programas o las aplicaciones que respondían a nuestra búsqueda, incluso puede que 
algunos de ellos desaparezcan con el tiempo y que no tengan ningún soporte científico en sus descripciones. No obstante, es nuestro deber explicar el proceso de obtención de la información. Para ello, se ha entrado directamente a cada uno de los sitios web y se ha buscado en la primera página que aparece en pantalla el nombre de aplicaciones o de programas que respondan a nuestras necesidades de indagación en gamificación. Después de revisar uno a uno los cinco sitios mencionados, se ha procedido al registro (en un cuaderno de notas) de los nombres de las herramientas encontradas para su posterior clasificación, teniendo en cuenta sus objetivos y su incidencia en las características recomendadas para fomentar un entorno lúdico en el aula virtual o física.

Con el objetivo de delimitar el corpus de estudio de este trabajo, se ha procedido a un análisis de las características generales de las 23 herramientas obtenidas de la indagación previa con el propósito de clasificarlas según su tipo y objetivo. Para realizar dicha tarea, se ha utilizado el mismo buscador (Google) con la finalidad de obtener información de la página oficial de cada herramienta y verificar su existencia, así como para probar algunas de sus funciones. En cada una de las 23 aplicaciones se ha accedido a sus funciones para determinar el tipo de herramienta en cuestión, teniendo en cuenta sus características visuales y pruebas simples de uso (sin un contexto didáctico en particular). Desde la página principal, en la mayoría de estos sitios web se puede apreciar el tipo de herramienta que se ofrece y algunas de las características y posibilidades didácticas para la gamificación. Por ejemplo, en el caso de Minecraft Education, el sitio ofrece, en su primera interfaz, una descripción general y algunos vídeos que permiten determinar el tipo de herramienta y su aplicación en el aula. De la misma manera, para la obtención de la información sobre el posible objetivo educativo, se ha utilizado la información disponible en cada sitio web para su clasificación en el cuadro 2.

Cuadro 2. Clasificación de herramientas según su tipo y objetivo

Herramientas

Brainscape

Knowre

Cerebriti

Minecraft

PearDeck

Kahoot!

Edmodo
Tipo

Objetivo educativo

Plataforma de creación de tarjetas (flashcard). No definido.

Matemáticas.

No definido.

No definido.

No definido.

No definido.

No definido. 


\begin{tabular}{|c|c|c|}
\hline Herramientas & Tipo & Objetivo educativo \\
\hline \multicolumn{3}{|l|}{ 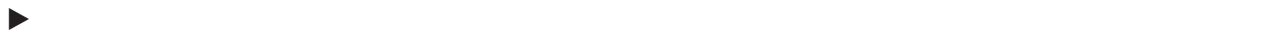 } \\
\hline Classcraft & Plataforma para gestión de juego de rol. & No definido. \\
\hline CodeCombat & Videojuego. & Informática y programación. \\
\hline ClassDojo & Plataforma de gestión de comportamiento. & No definido. \\
\hline ChemCaper & Videojuego (juego de rol). & Química. \\
\hline Quizlet & Plataforma de creación de tarjetas (flashcard). & No definido. \\
\hline Toovari & Plataforma gamificada. & Ciencias y matemáticas. \\
\hline $\begin{array}{l}\text { The World Peace } \\
\text { Game }\end{array}$ & Juego de rol (simulación global). & Ética, valores y paz. \\
\hline Play Brighter & Plataforma para gestión de juego de rol. & No definido. \\
\hline Quizizz & Test interactivos (quizzes). & No definido. \\
\hline Monsterkit & Juego de mesa. & $\begin{array}{l}\text { Inteligencias lógico-matemática, } \\
\text { espacial, artística y lingüística. }\end{array}$ \\
\hline Trivinet & Test interactivos (quizzes). & No definido. \\
\hline Arcademics & Videojuegos. & Matemáticas, lenguas y arte. \\
\hline Genially & Diseño de materiales visuales y audiovisuales. & No definido. \\
\hline FlipQuiz & Tableros de preguntas. & No definido. \\
\hline Socrative & Test interactivos (quizzes). & No definido. \\
\hline uLearn Play & Aplicación móvil para gamificación. & Ámbito corporativo. \\
\hline
\end{tabular}

Fuente: elaboración propia.

Al revisar los resultados del cuadro 2, podemos apreciar que la mayoría de las herramientas encontradas no disponen de un objetivo establecido. Esto resulta importante, pues el uso de cada aplicación se extiende a diferentes contextos didácticos y no solamente a instituciones educativas. Los datos obtenidos evidencian que 15 de las 23 
aplicaciones presentan mayor libertad en sus objetivos educativos, el resto se dirige a públicos particulares; por ejemplo, CodeCombat está enfocada en estudiantes interesados en la programación web.

Después de esta clasificación, el estudio se ha centrado en determinar las aplicaciones didácticas de cada herramienta en relación con la metodología de gamificación. Para realizar este estudio, se ha accedido a los sitios oficiales de los diferentes programas y se han realizado pruebas de sus funciones, verificando las posibilidades didácticas para la gamificación. Se han elaborado una serie de cuadros para clasificar la información, tomando como referencia los trabajos realizados en esta materia por Werbach y Hunter (2012) (citados en Alejaldre y García, 2015), que profundizan en la concepción de entornos ludificados mediante la integración de dinámicas, mecánicas y componentes (véanse cuadros $3,4,5$ y 6).

Cuadro 3. Clasificación de herramientas en función de las dinámicas

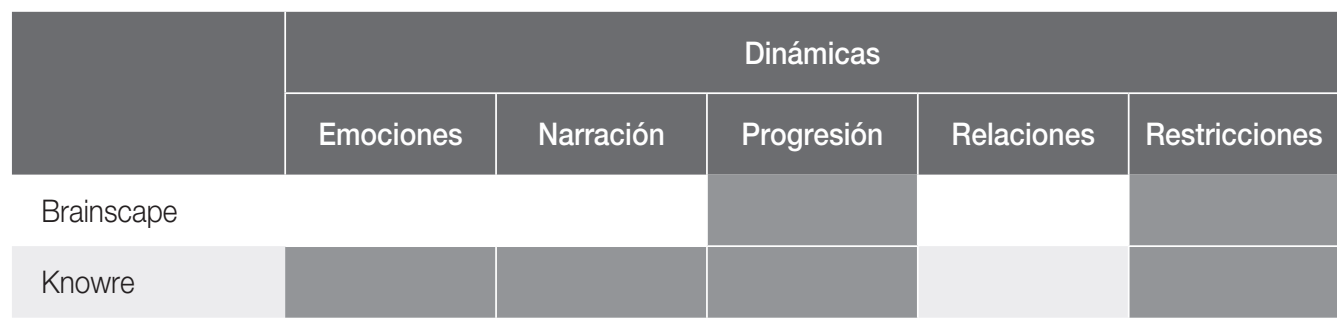

Cerebriti

Minecraft

PearDeck

Kahoot!

Edmodo

Classcraft

CodeCombat

ClassDojo

ChemCaper

Quizlet

Toovari
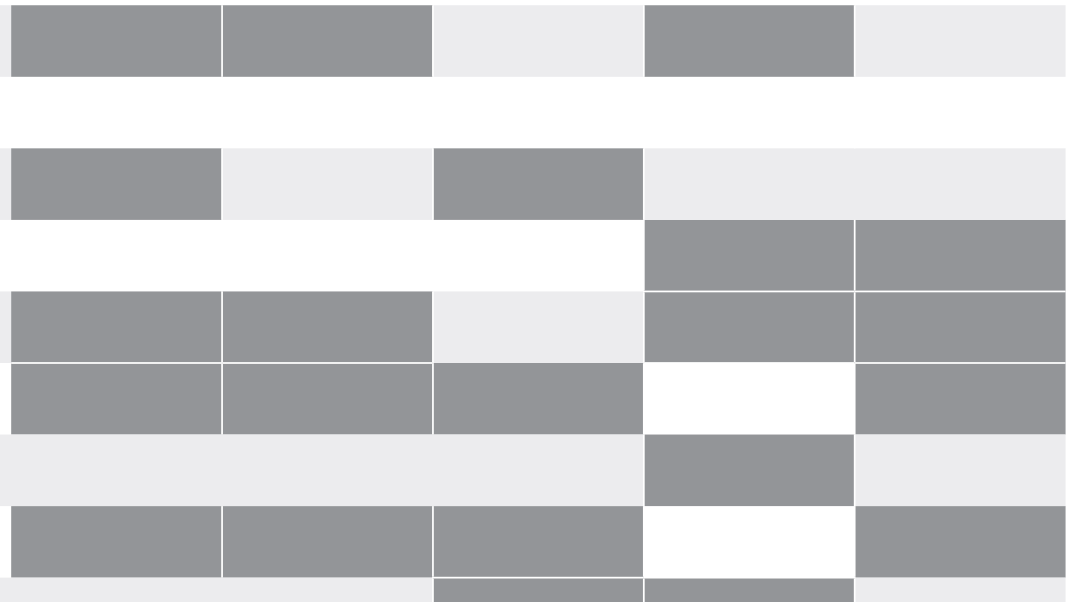


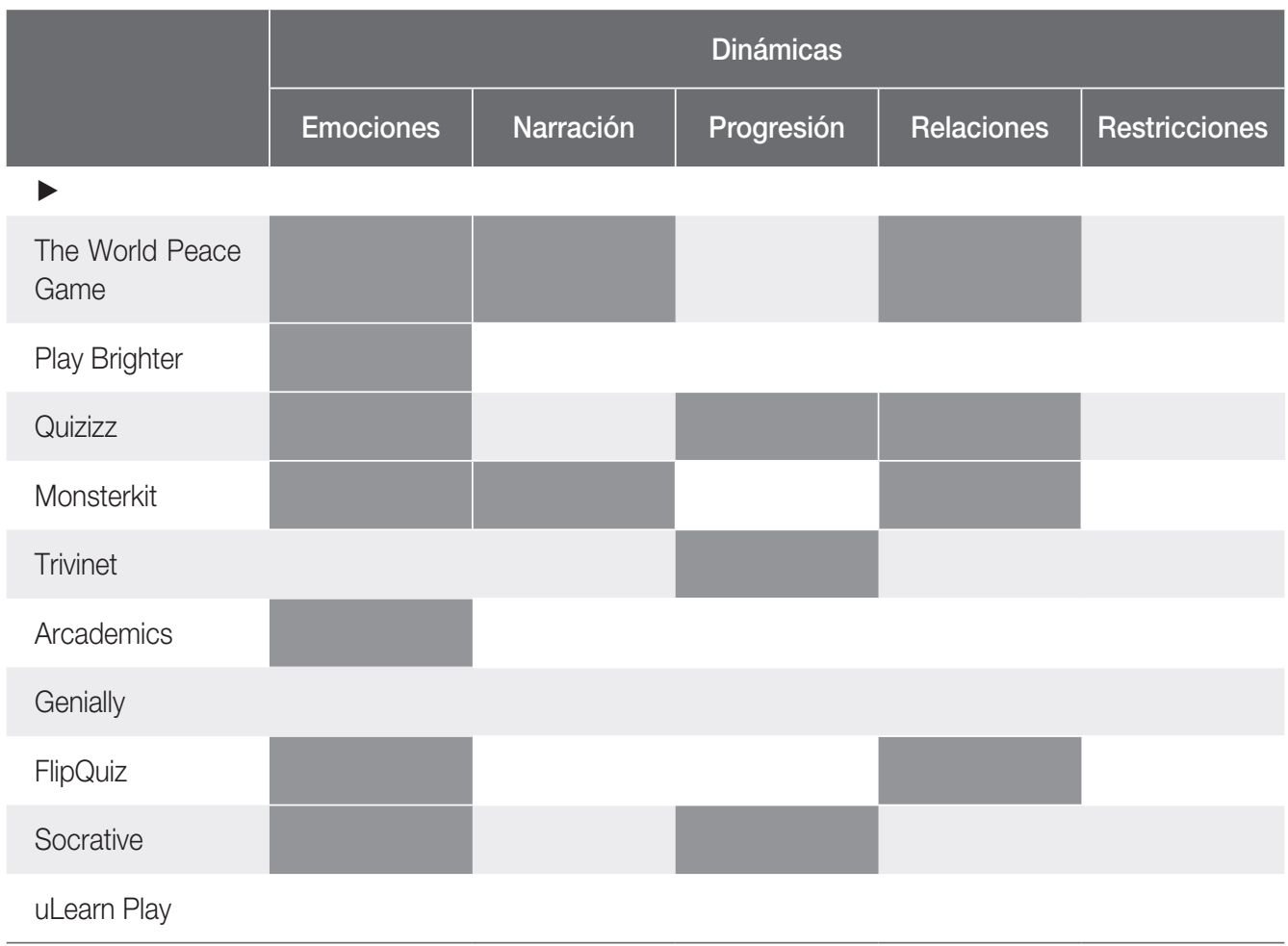

Fuente: elaboración propia.

Cuadro 4. Clasificación de herramientas en función de las mecánicas

\begin{tabular}{|c|c|c|c|c|c|c|c|}
\hline \multicolumn{8}{|c|}{ Mecánicas } \\
\hline Colaboración & Competición & Desafíos & Recomp. (1) & Retroal. (2) & Suerte & Transac. (3) & Turnos \\
\hline
\end{tabular}

Brainscape

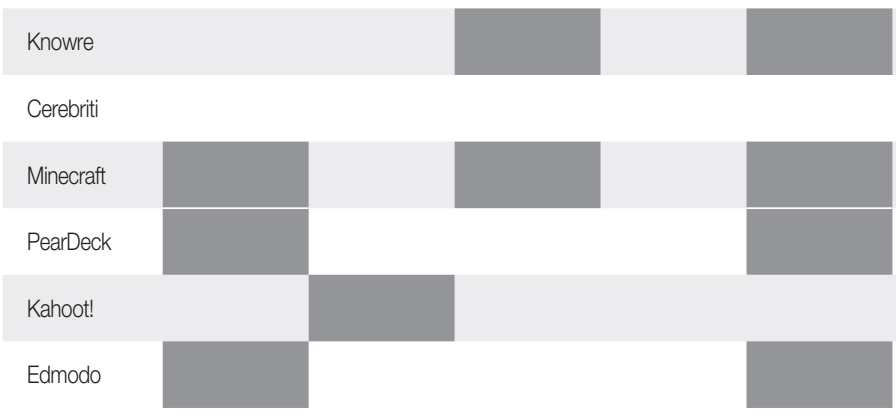




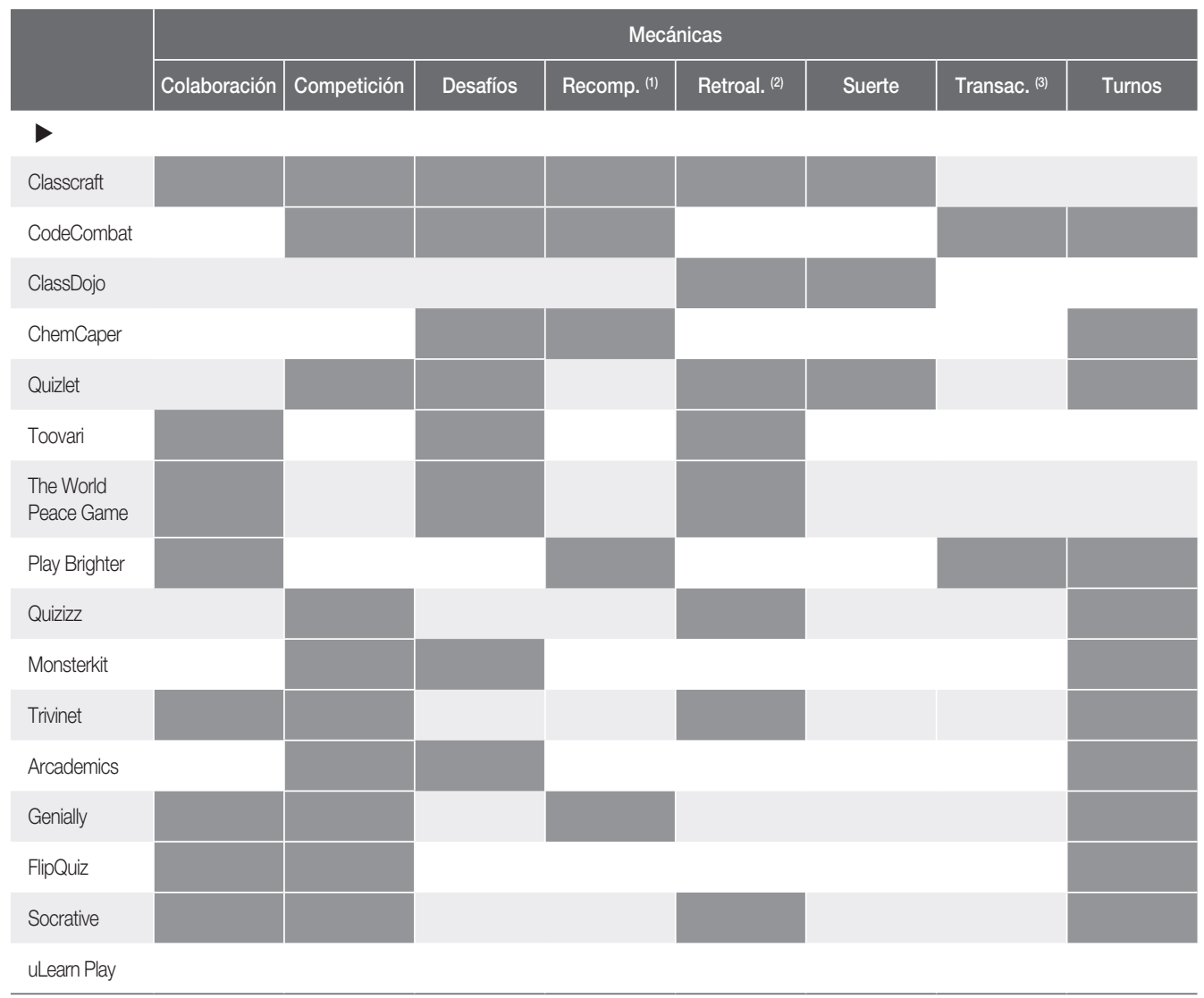

(1) Recompensa

(2) Retroalimentación.

(3) Transacciones.

Fuente: elaboración propia.

Cuadro 5. Clasificación de herramientas en función de los componentes (1)

\begin{tabular}{|c|c|c|c|c|c|c|c|c|}
\hline & \multicolumn{8}{|c|}{ Componentes } \\
\hline & Avatar & Colecciones & Combate & $\begin{array}{l}\text { Desbloqueo } \\
\text { contenidos }\end{array}$ & Equipos & $\begin{array}{l}\text { Gráficas } \\
\text { sociales }\end{array}$ & $\begin{array}{c}\text { Huevos de } \\
\text { Pascua }\end{array}$ & Insignias \\
\hline \multicolumn{9}{|c|}{ Brainscape } \\
\hline \multicolumn{9}{|l|}{ Knowre } \\
\hline \multicolumn{9}{|l|}{ Cerebriti } \\
\hline Minecraft & & & & & & & & \\
\hline
\end{tabular}




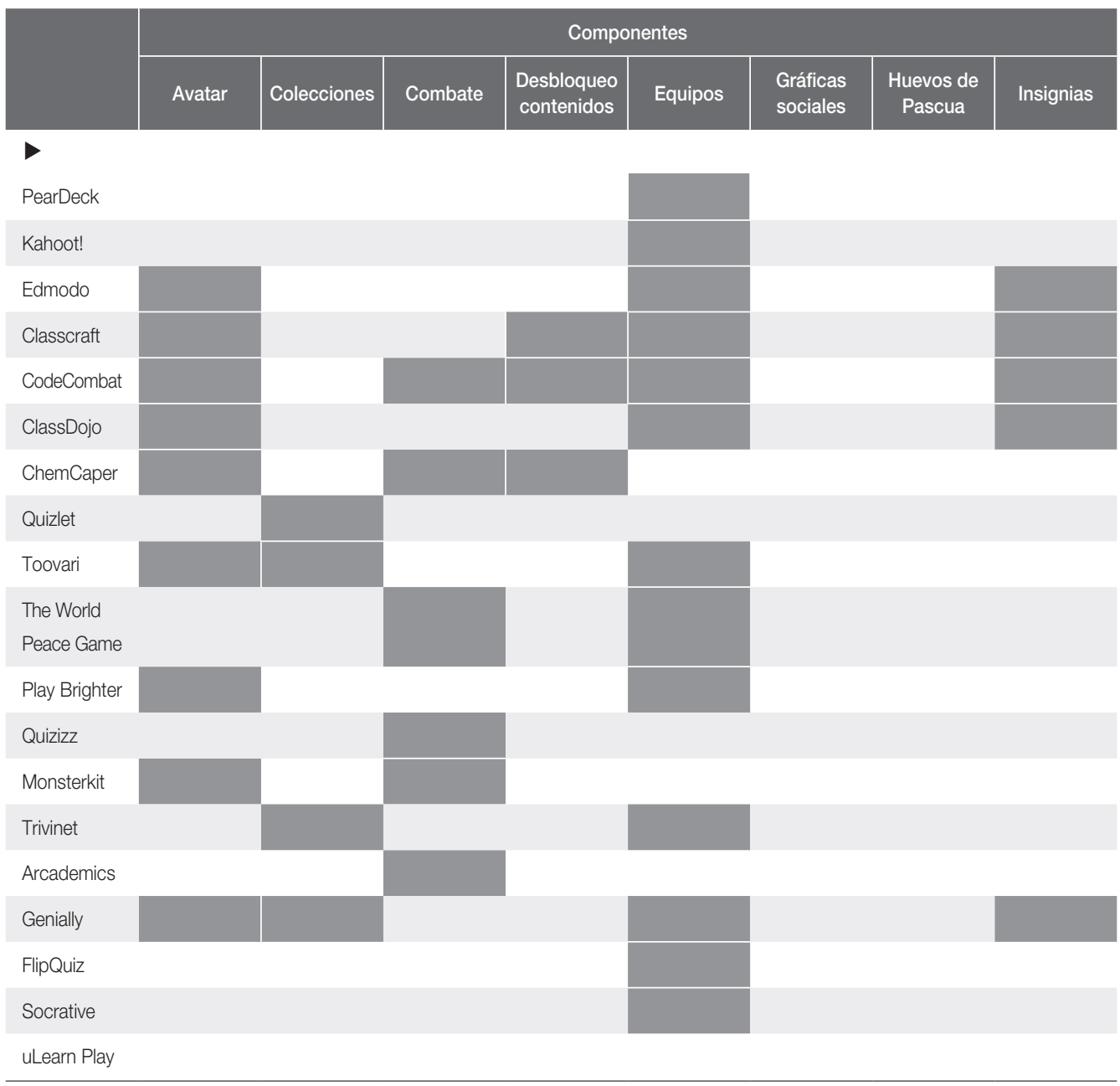

Fuente: elaboración propia.

Cuadro 6. Clasificación de herramientas en función de los componentes (2)

\begin{tabular}{|c|c|c|c|c|c|c|c|}
\hline & \multicolumn{7}{|c|}{ Componentes } \\
\hline & $\begin{array}{l}\text { Límites de } \\
\text { tiempo }\end{array}$ & Misiones & Niveles & Puntos & Clasificaciones & Regalos & Tutoriales \\
\hline \multicolumn{8}{|c|}{ Brainscape } \\
\hline \multicolumn{8}{|l|}{ Knowre } \\
\hline Cerebriti & & & & & & & \\
\hline
\end{tabular}




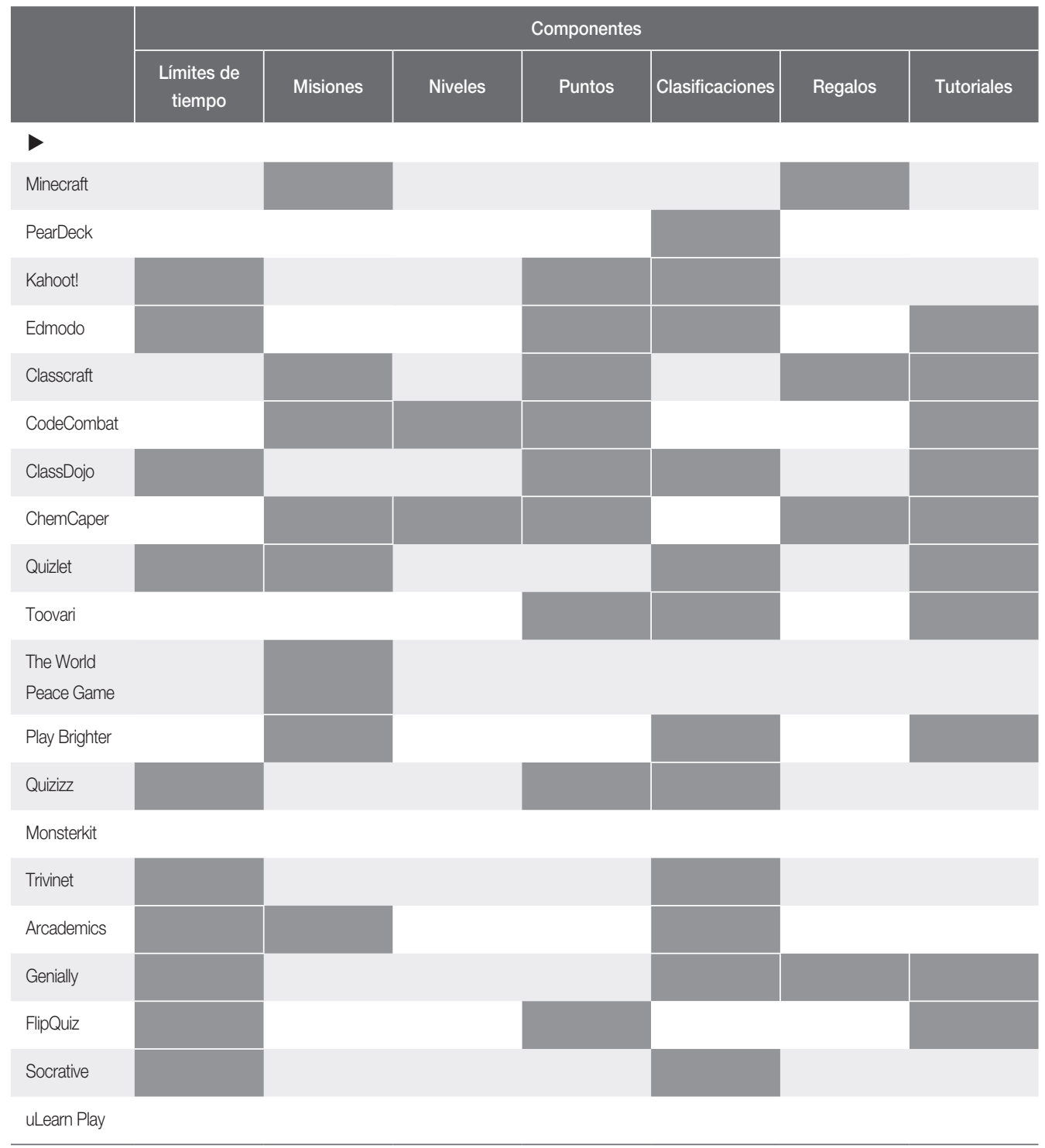

Fuente: elaboración propia.

Las casillas con trama gris oscuro de los cuadros 3, 4, 5 y 6 evidencian la incidencia de las herramientas en las dinámicas, en las mecánicas y en los componentes de la gamificación. Para obtener esta información, analizamos una a una las aplicaciones, probando sus funciones y estudiando sus posibilidades a la hora de cumplir con los criterios o con las características de la metodología de gamificación. Por ejemplo, en el caso de Quizizz, nos encontramos con un entorno de competición, ya que todos los jugadores juegan al mismo 
tiempo y ganan los que obtengan mejor puntuación. Se ofrece también la posibilidad de retroalimentación después de cada pregunta. Hay límites de tiempo para las respuestas y se asignan puntos. De esta manera, la prueba y el uso de las diferentes funciones ha permitido determinar la incidencia de cada herramienta en las diferentes categorías de los cuadros 3 , 4,5 y 6 . Cabe agregar que otros trabajos han realizado prácticas similares de análisis, lo que supone que la clasificación de las herramientas se enriquezca con diferentes percepciones sobre el tema en cuestión. Considerando esta perspectiva, resaltamos el trabajo realizado por García e Hijón (2017), quienes ofrecen un referente similar al nuestro, en el que se clasifican diferentes plataformas en función de su impacto en gamificación y su posibilidad de integración con otras herramientas digitales externas.

Con respecto a este trabajo, los resultados arrojados muestran que en ninguna de las herramientas clasificadas intervienen todos los elementos de la perspectiva didáctica estudiada. Dicha información nos permite afirmar que para construir un entorno que reúna la mayor parte de las particularidades de la gamificación es

Los resultados arrojados muestran que en ninguna de las herramientas clasificadas intervienen todos los elementos de la perspectiva didáctica estudiada necesario utilizar varias herramientas y dispositivos con el fin de construir el ambiente ludificado; esto considerando los criterios establecidos por Werbach y Hunter (2012) (citados en Alejaldre y García, 2015) y los cinco niveles de elementos de diseño de juegos explicados por Deterding, Dixon, Kalhed y Nacke (2014). Sin embargo, pensamos que esta situación no representa gran dificultad para los profesores que están dispuestos a usar diversos materiales en la construcción del entorno lúdico, y esto podría considerarse como una oportunidad para ofrecer mayor diversidad de actividades innovadoras.

También, esta organización nos ha permitido observar que las herramientas que tienen mayor implicación en las dinámicas, en las mecánicas y en los componentes de gamificación son las aplicaciones de tipo juego y videojuego (véanse cuadros 2, 3, 4, 5 y 6). Aunque los juegos podrían integrarse en la progresión de un curso ludificado, en este caso, ya tienen un objetivo específico de aprendizaje y estimamos que corresponderían de mejor manera a la perspectiva de aprendizaje basado en juegos que a la gamificación.

Ahora bien, en la última etapa del procesamiento de datos, con el propósito de acotar nuestro análisis, se seleccionaron solo tres herramientas para la última parte de este estudio, considerando la diversidad, la aplicación integral y la libertad de manipulación de funciones en los distintos programas clasificados. Aunque el análisis en extenso de todas las herramientas resultantes de la indagación podría ser enriquecedor, hemos seleccionado las aplicaciones considerando los tres criterios aludidos y el objetivo principal de este trabajo: ofrecer un referente práctico que esclarezca funciones de algunas herramientas aplicables a la metodología en cuestión. Además, el hecho de analizar en detalle cada uno de los resultados implicaría que este documento fuera demasiado extenso y dificultaría la comprensión de los lectores. No obstante, nuestra intención es también que otros inves- 
tigadores aporten sus conocimientos sobre este tema y que puedan enriquecer este tipo de trabajos estudiando el funcionamiento del resto de aplicaciones resultantes de nuestro proceso de investigación o que estudien otras herramientas siguiendo la propuesta de trabajos similares al nuestro. Dicho esto, hemos seleccionado para nuestro análisis posterior las herramientas Pear Deck, Classcraft y Quizizz sin desestimar el potencial del resto. Creemos que estas aplicaciones digitales cumplen con los requisitos de nuestro objetivo de estudio: la comprensión de nuevas tecnologías para la gamificación aplicadas a diversos ámbitos educativos.

Además, hemos considerado en nuestra selección los trabajos de Corchuelo-Rodríguez (2018) y Sierra y Juste (2018), quienes estudian las funciones de algunas de las aplicaciones resultantes de este estudio. Así, buscamos enriquecer el ámbito con nuestra selección para complementar las habilidades docentes y los referentes descriptivos de esta área.

Por otra parte, los cuatro instrumentos seleccionados disponen de características distintivas que podrían ser utilizadas en conjunto en un ambiente ludificado. Cada una de ellas tiene un objetivo diferente y podrían complementarse en sus carencias. No obstante, resultaría de gran interés que se realizaran estudios posteriores sobre las herramientas encontradas en la indagación y otras que podrían resultar enriquecedoras para la perspectiva en cuestión. Considerando esta situación, explicamos, a continuación, el proceso de selección:

- Teniendo en cuenta la perspectiva de gamificación y no la de aprendizaje basado en juegos, hemos descartado el análisis de todas las herramientas que tienen un objetivo educativo preestablecido (juegos y videojuegos). En total se encontraron 8 aplicaciones con esta situación (véase cuadro 2).

- De las plataformas para la gestión de premios, misiones e insignias, hemos seleccionado Classcraft. Estimamos que esta plataforma ofrece una perspectiva interesante que integra el juego de rol en un sistema atractivo que podría motivar a los estudiantes a mostrar un comportamiento y acciones conforme a un reglamento y criterios establecidos. En total encontramos 4 plataformas con estas posibilidades, pero nos hemos inclinado por Classcraft por su propuesta de gestión de conductas, considerando también que actualmente Edmodo ya ha sido estudiada y aplicada por un mayor número de académicos, como es el caso de Mathupayas (2013) y de Balasubramanian, Jaykumar y Nitin (2014). En lo que se refiere a los dos restantes, Playbrigther ofrece menos libertades que Classcraft en algunos rubros y ClassDojo se enfoca más a niños en un esquema de seguimiento que implica a los tutores.

- Para el caso de los instrumentos que ayudan en la creación de pruebas o quizzes, consideramos que Quizizz es una opción interesante que permite integrar aspectos lúdicos de motivación que podrían enriquecer la integración de la gamificación. A diferencia de Trivinet y FlipQuiz, Quizizz ofrece un mayor número de 
herramientas. Para esta decisión, consideramos también los antecedentes de otros estudios en los que ya se analizaron las herramientas restantes (Kahoot! y Socrative); por ejemplo, los trabajos de Baldeón, Rodríguez, Puig y LópezSánchez (2017).

- Hemos considerado que aplicaciones como Genially, Quizlet, Brainscape y Cerebriti resultan enriquecedoras para la perspectiva didáctica en cuestión; no obstante, al ser herramientas que permiten crear materiales digitales visuales y audiovisuales, consideramos que se requiere de su estudio específico en otra investigación en la que se analicen también las teorías de diseño multimedia, buscando así concretar un referente más que distinga todo su potencial didáctico. Por otra parte, en el caso de Minecraft, creemos que esta herramienta compleja requiere de un estudio profundo e individual que permita esclarecer todas sus opciones y sus posibles usos en el ámbito educativo. Por último, para la herramienta uLearn Play no fue posible realizar pruebas debido a su acceso privado, por lo que la información del cuadro 2 fue extraída del sitio oficial de la aplicación y no se pudieron revisar sus diferentes funciones.

En resumen, nuestros criterios de selección consideran la perspectiva del estudio y nuestro interés, en particular, por esclarecer y contribuir a la comprensión tecnológica de estos instrumentos con un enfoque integral, pero, en ningún caso, buscamos menospreciar las funciones del resto de las herramientas clasificadas en nuestra indagación previa y no desestimamos la posibilidad de construir otro referente en el futuro que permita estudiar sus capacidades educativas.

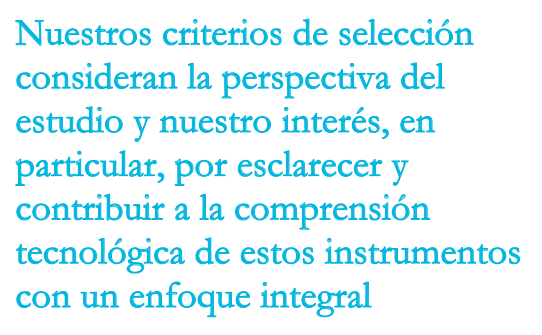

\section{Análisis}

Con el objetivo de explicar las características principales de las herramientas mencionadas en el apartado anterior, proponemos un análisis dividido en los siguientes puntos:

- Descripción general.

- Usos en gamificación.

- Limitaciones e inconvenientes.

- Evaluación de usabilidad.

- Nivel de incidencia en la gamificación. 


\subsection{Pear Deck}

\subsubsection{Descripción general}

Pear Deck es una herramienta destinada principalmente al desarrollo de presentaciones digitales interactivas. Para hacer uso de sus funciones se requiere acceder al sitio web $<$ https://www.peardeck.com/> (para poder hacer uso de sus opciones hay que tener abierta una cuenta de Google). Esto es debido a que el sistema se alimenta de los documentos creados en las aplicaciones de Google. El sistema dispone de dos tipos de cuenta: profesor y estudiante. La primera cuenta, destinada a los docentes, permite la creación y gestión de las presentaciones para su posible integración en sistemas de proyección digital. En el caso de la cuenta de estudiante, esta se utiliza para comunicar con la presentación del profesor y posibilitar la interacción entre las actividades propuestas cuando la presentación está en funcionamiento. Cabe mencionar que una de las funciones que distingue a Pear Deck de otras herramientas de diseño es, precisamente, la posibilidad de que los estudiantes interactúen con la presentación. Mediante opciones preestablecidas en el proceso de diseño, el profesor podrá crear diapositivas con actividades interactivas en el aula.

Para el control y la visualización de la presentación, el estudiante insertará en su equipo un código proporcionado por el profesor para así realizar las actividades interactivas (véase figura 1).

Figura 1. Pantalla del profesor e interfaz de ingreso del estudiante

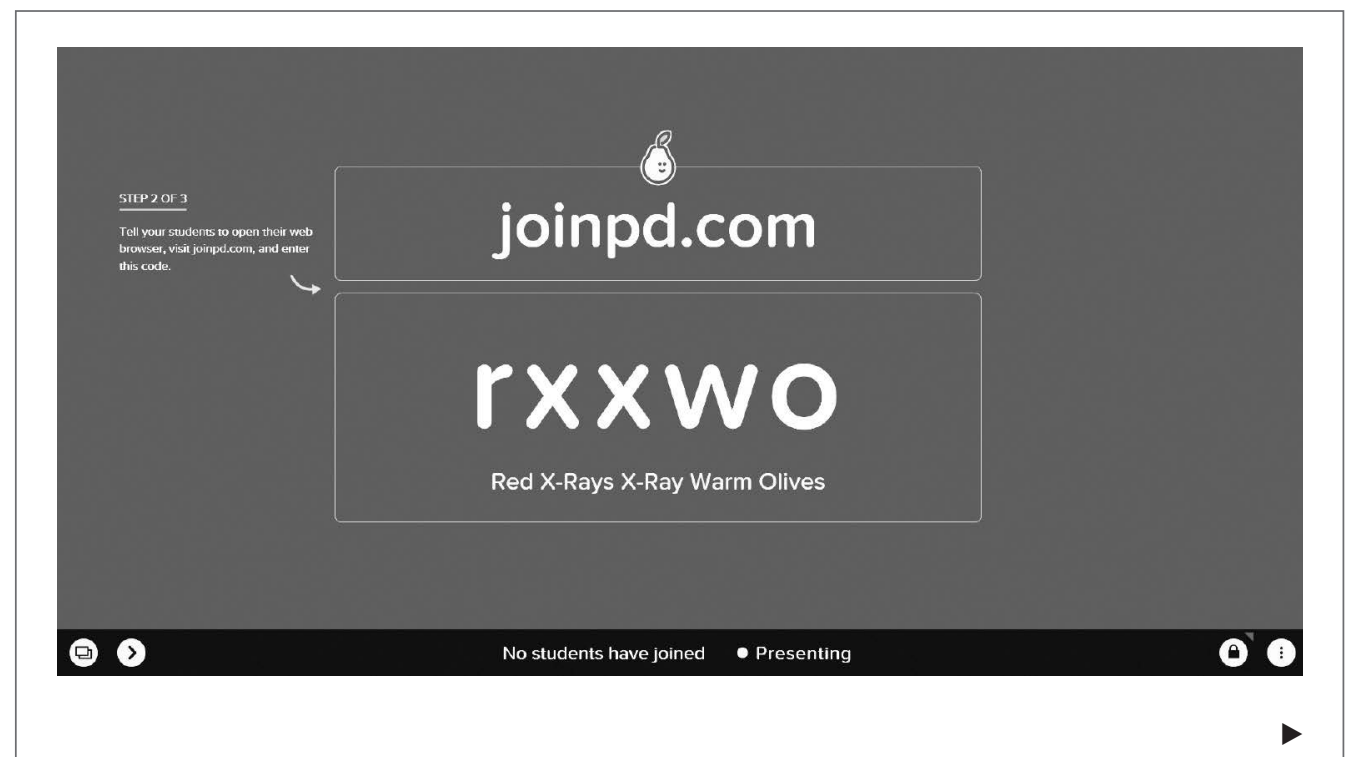




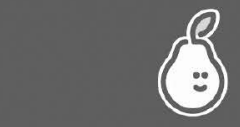

Red X-Rays X-Ray Warm Olives

Fuente: elaboración propia

Entre los tipos de acciones que el estudiante puede realizar durante la presentación se encuentra la inserción de datos correspondientes a los tipos de respuesta: texto corto, opción múltiple, dibujo, números, entre otros. Dichas acciones corresponden a las actividades durante la visualización de diapositivas, en las que los estudiantes podrán enviar información a la presentación. Esta información será recibida por el profesor y proyectada a través del medio de reproducción utilizado (véase figura 2).

Figura 2. Pantallas del profesor y del estudiante

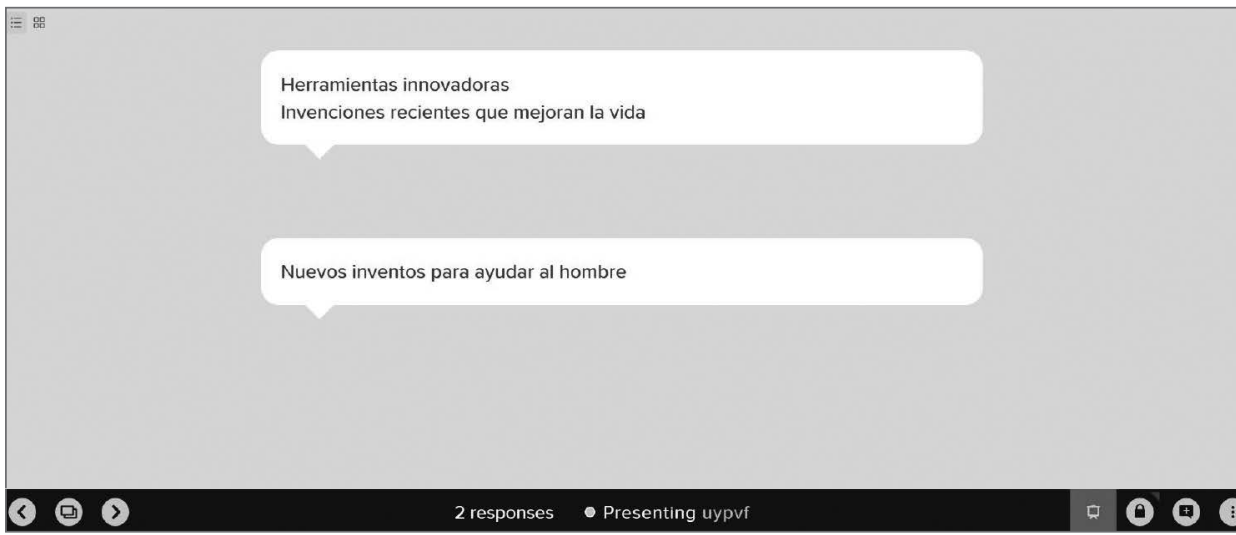




\section{¿Qué es tecnología?}
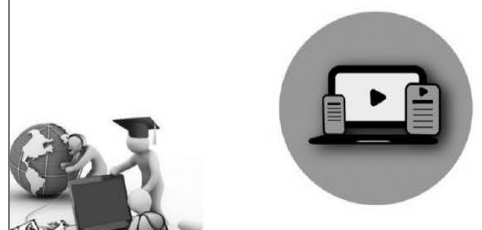

Herramientas innovadoras

Invenciones recientes que mejoran la vida

Fuente: elaboración propia.

Pear Deck funciona como un complemento en Google Docs y posibilita diferentes alternativas visuales y acciones interactivas con los estudiantes para gestionar su participación en la presentación. Cabe mencionar que la mayoría de las opciones de diseño son proporcionadas por las herramientas de Google.

Pear Deck permite agregar solamente características visuales y espacios de interactividad en el medio digital. La mayoría de las diapositivas interactivas vienen preconfiguradas para que el profesor edite la pregunta o el tipo de actividad que desea integrar en la presentación.

Finalmente, además de facilitar la interacción de los estudiantes en el aula, Pear Deck ofrece la herramienta de creación de tarjetas de aprendizaje (flashcards) mediante una aplicación que deja trabajar a los estudiantes (individualmente o en equipo) en conceptos para crear diseños de tarjetas que deberán ser validadas por el docente al término de la actividad (véase figura 3). 
Figura 3. Interfaz de creación de cartas de aprendizaje del estudiante e interfaz de revisión del profesor

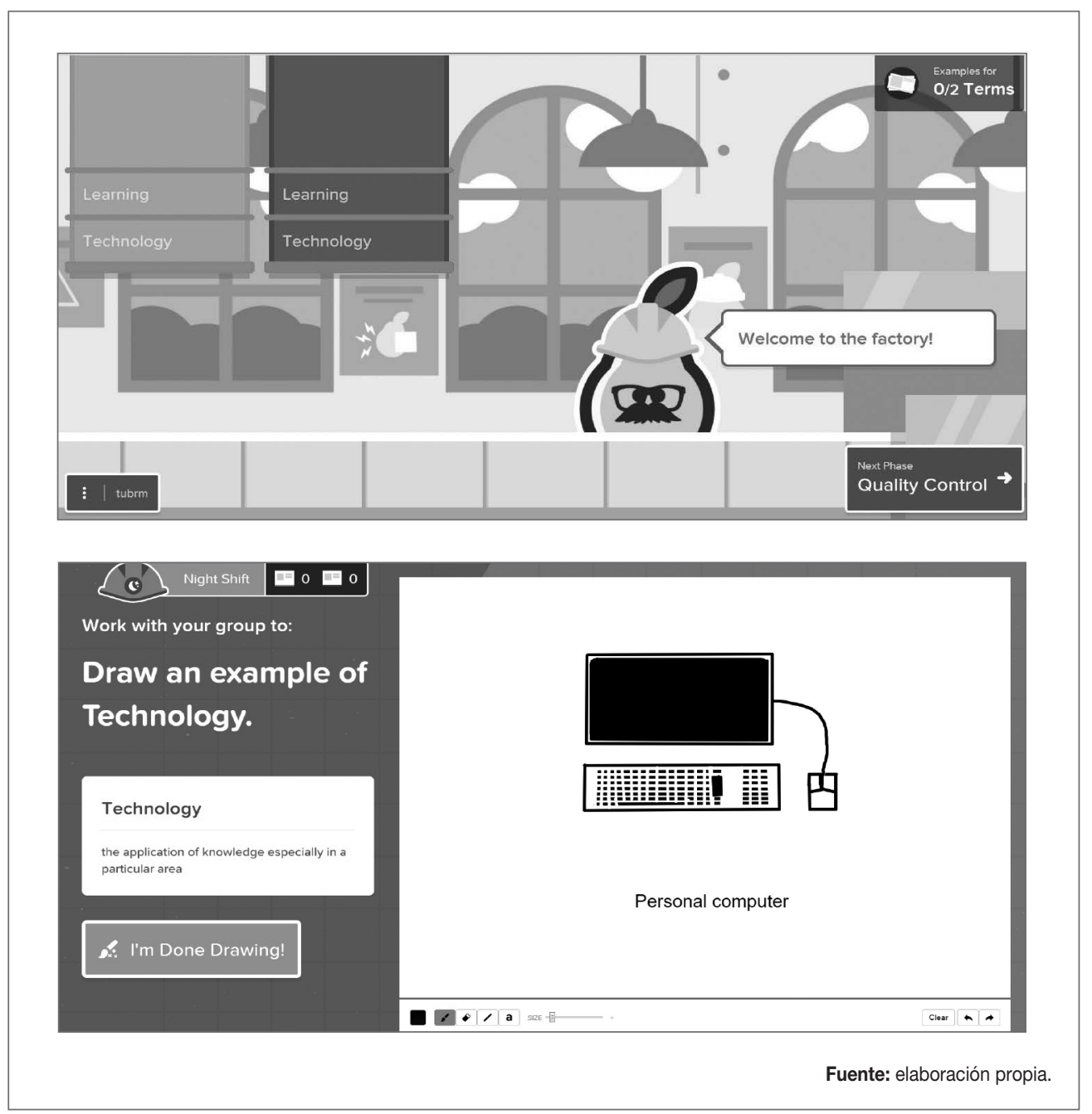

En cuanto a esta herramienta de creación, resulta interesante mencionar que las creaciones de los estudiantes pueden ser ligadas a una cuenta de Quizlet, plataforma de gestión y diseño de tarjetas de aprendizaje.

\subsubsection{Usos en gamificación}

En relación con la gamificación, consideramos que Pear Deck facilita un espacio de interacción en el aula que podría ser utilizado para motivar la participación y la colaboración. De 
esta manera, creemos que la aplicación podría incidir en las mecánicas correspondientes al trabajo colaborativo y, a su vez, en las emociones: curiosidad, competitividad, felicidad, etc. También, estimamos que la herramienta podría impactar en el desarrollo de las relaciones (interacciones y compañerismo) cuando se realizan actividades en equipo. Con los recursos colaborativos que ofrece la herramienta se podrían crear concursos o competencias con la ayuda de las presentaciones interactivas o mediante la interfaz de creación de tarjetas. Dichas actividades podrían ser relacionadas con otros componentes y mecánicas de gamificación a partir de la inclusión de insignias, regalos, turnos, entre otros (véanse cuadros 3, 4, 5 y 6).

\subsubsection{Limitaciones e inconvenientes}

Partiendo del análisis de funciones, creemos que Pear Deck es una herramienta práctica que podría incidir de manera positiva en la gamificación. Sin embargo, consideramos que esta herramienta limita los entornos didácticos, obligando al uso de equipos informáticos a todos los participantes en el aula. Esta situación podría repercutir en los centros educativos que no disponen de aulas de informática con equipos suficientes para todos los participantes. Por otra parte, pensamos que el uso de ciertas herramientas para el diseño de las diapositivas podría resultar complejo para aquellos profesores que no utilizan regularmente las aplicaciones de Google. Además, la necesidad de hacer uso de diferentes ventanas para generar y configurar las preguntas de las dos plataformas (Google y Pear Deck) podría complicar el desarrollo de las diapositivas. También, resulta interesante resaltar que no encontramos una opción que permita previsualizar y probar las configuraciones, por lo que el diseñador deberá hacer uso de diferentes ventanas con dos cuentas (profesor y estudiante) para verificar el funcionamiento correcto de la presentación.

En síntesis, al ser una plataforma que utiliza las funciones de la herramienta Google Slides, se requieren conocimientos y competencias para poder hacer un uso adecuado de las funcionalidades de la aplicación Pear Deck. A esto, se suma la necesidad de tener una cuenta de Google para poder utilizar sus funciones.

\subsubsection{Evaluación de las características de usabilidad web y gamificación}

Con el objetivo de obtener una visión más precisa del funcionamiento de cada herramienta estudiada, proponemos una evaluación tanto de la usabilidad web para el diseño de materiales digitales como de la implicación de patrones de juego para el desarrollo de ambientes de gamificación. Para llevar a cabo la evaluación que califica el nivel de atención de los criterios de gamificación y de los patrones de diseño de juego, hemos establecido las siguientes categorías:

- Adecuada. Para los medios tecnológicos que cumplen ampliamente con los criterios o características señalados. 
- Suficiente. Para aquellos criterios que presentan carencias, pero permiten un funcionamiento correcto del sistema.

- Insuficiente. Para aquellos casos en los que el sistema, desde nuestra perspectiva y uso, requiere mayor atención para atender las necesidades de un entorno digital o no se presentan elementos que evidencien patrones de diseño de juego.

Es importante mencionar que para elaborar este cuadro se han utilizado los trabajos sobre criterios de usabilidad y ergonomía estudiados por Colomba (2006), así como los patrones de diseño de juego explicados por Deterding et al. (2014).

\section{Cuadro 7. Evaluación de la usabilidad y de los patrones de juego de la experiencia con la herramienta Pear Deck}

\begin{tabular}{|c|c|c|c|}
\hline Criterios & \multicolumn{3}{|c|}{ Escala de evaluación } \\
\hline 1. Aprendizaje & $\begin{array}{l}\text { Familiaridad (adecuado): la } \\
\text { mayoría de los elementos } \\
\text { presentes en la interfaz son } \\
\text { de uso común o pueden ser } \\
\text { aprendidos fácilmente. }\end{array}$ & $\begin{array}{l}\text { Familiaridad (suficiente): algu- } \\
\text { nas opciones podrían resultar } \\
\text { difíciles de comprender, pero } \\
\text { se pueden aprender fácilmen- } \\
\text { te con poco tiempo de uso. }\end{array}$ & $\begin{array}{l}\text { Familiaridad (insuficiente): la } \\
\text { plataforma requiere de un uso } \\
\text { constante para poder apren- } \\
\text { der el funcionamiento de sus } \\
\text { diferentes opciones. }\end{array}$ \\
\hline 2. Operatividad & $\begin{array}{l}\text { Manipulación (adecuado): el } \\
\text { sistema ofrece un alto grado } \\
\text { de manipulación de las fun- } \\
\text { ciones y el usuario puede uti- } \\
\text { lizarlas con un alto grado de } \\
\text { libertad. }\end{array}$ & $\begin{array}{l}\text { Manipulación (suficiente): el } \\
\text { sistema permite el funciona- } \\
\text { miento y manipulación de los } \\
\text { elementos con cierto grado } \\
\text { de libertad, pero algunas fun- } \\
\text { ciones son limitadas. }\end{array}$ & $\begin{array}{l}\text { Manipulación (insuficiente): el } \\
\text { sistema ofrece poca flexibili- } \\
\text { dad al usuario. No existe varie- } \\
\text { dad de opciones disponibles o } \\
\text { el funcionamiento podría com- } \\
\text { plicar la manipulación. }\end{array}$ \\
\hline 3. Satisfacción & $\begin{array}{l}\text { Sensación de satisfacción } \\
\text { (adecuado): la interacción } \\
\text { entre el sistema y el usua- } \\
\text { rio es fluida. No se requieren } \\
\text { muchas tareas por parte del } \\
\text { usuario para obtener una res- } \\
\text { puesta. El aspecto es agrada- } \\
\text { ble y ergonómico. Se requiere } \\
\text { poca experiencia en la materia } \\
\text { para hacer un uso adecuado } \\
\text { de la aplicación. }\end{array}$ & $\begin{array}{l}\text { Sensación de satisfacción } \\
\text { (suficiente): la interacción } \\
\text { entre el sistema y el usuario } \\
\text { es adecuada, pero la organi- } \\
\text { zación de algunos elementos } \\
\text { dificulta el uso de la aplicación } \\
\text { y se requiere de experiencia } \\
\text { previa en el medio para com- } \\
\text { prender el funcionamiento. El } \\
\text { aspecto es agradable y tiene } \\
\text { cierto grado de ergonomía. }\end{array}$ & $\begin{array}{l}\text { Sensación de satisfacción (in- } \\
\text { suficiente): la interacción entre } \\
\text { el sistema y el usuario resulta } \\
\text { complicada o compleja. Los } \\
\text { resultados obtenidos median- } \\
\text { te el uso de las funciones re- } \\
\text { quieren de un mayor número } \\
\text { de tareas. El aspecto no resul- } \\
\text { ta agradable o ergonómico. }\end{array}$ \\
\hline 4. Contenido & $\begin{array}{l}\text { Claridad en la organización y } \\
\text { presentación de contenidos } \\
\text { (adecuado): los contenidos } \\
\text { pueden ser comprendidos }\end{array}$ & $\begin{array}{l}\text { Claridad en la organización y } \\
\text { presentación de contenidos } \\
\text { (suficiente): ciertos contenidos } \\
\text { pueden ser comprendidos con }\end{array}$ & $\begin{array}{l}\text { Claridad en la organización y } \\
\text { presentación de contenidos } \\
\text { (insuficiente): los contenidos } \\
\text { no son claros o resulta difícil }\end{array}$ \\
\hline
\end{tabular}




\begin{tabular}{|l|l|}
\hline Criterios & \\
\hline $\begin{array}{ll}\text { 4. Contenido } \\
\text { (cont.) }\end{array}$ & $\begin{array}{l}\text { fácilmente y existe compati- } \\
\text { bilidad con diferentes clientes } \\
\text { web. El sistema se ofrece en } \\
\text { diferentes idiomas. }\end{array}$ \\
\hline 5. Eficiencia & $\begin{array}{l}\text { Tiempo de respuesta y nece- } \\
\text { sidad de ayudas (adecuado): } \\
\text { el tiempo de respuesta es } \\
\text { corto y no se requieren accio- } \\
\text { nes extra por parte del usua- } \\
\text { rio. El sistema es eficiente en } \\
\text { cuanto a su respuesta y el } \\
\text { fácil acceso a las funciones. }\end{array}$ \\
\hline
\end{tabular}

6. Eficacia

Percepción de recuperación y prevención de errores (adecuado): el sistema no presentó errores durante las pruebas y siempre se ofrecen mensajes de confirmación que ayudan a prevenir los posibles errores del usuario. La recuperación del error es ágil.

\section{Escala de evaluación}

cierta facilidad, pero no existe compatibilidad con diferentes clientes web. El contenido se ofrece en un solo idioma.

Tiempo de respuesta y necesidad de ayudas (suficiente): el tiempo de respuesta es corto, pero se requieren diversas acciones por parte del usuario para obtener la respuesta deseada. No es necesario hacer uso de ayudas para comprender el funcionamiento de la aplicación.

Percepción de recuperación y prevención de errores (suficiente): el sistema presenta algunos fallos o no se previenen errores mediante mensajes que ayuden al usuario a no cometerlos. La recuperación puede tardar en algunas ocasiones.

Presencia de elementos de juego adaptados a un problema o contexto dado: medallas, niveles y puntos (suficiente).

Inclusión de elementos propios del juego: límite de tiempo, recursos limitados, turnos, etc. (suficiente).

Inclusión de elementos para abordar un problema o una situación particular propuesta por el sistema: juegos, modalidades, objetivos, etc. (suficiente). comprender las diferentes funciones. No existe compatibilidad con diferentes clientes web y existe poco soporte en idiomas diferentes.

Tiempo de respuesta y necesidad de ayudas (insuficiente): el tiempo de respuesta entre el sistema y el usuario es largo o se requieren muchos pasos para obtener la respuesta esperada. Se requiere de información de ayuda constantemente para poder entender el funcionamiento de la aplicación.

Percepción de recuperación y prevención de errores (insuficiente): el sistema presenta muchos errores y lleva tiempo recuperarse de los fallos o es difícil regresar a un estado estable funcional. Los mensajes de errores no son claros o los medios no alertan sobre las decisiones que el usuario toma y que pudieran afectar a su trabajo.

Presencia de elementos de juego adaptados a un problema o contexto dado: medallas, niveles y puntos (insuficiente).

Inclusión de elementos propios del juego: límite de tiempo, recursos limitados, turnos, etc. (insuficiente).

Inclusión de elementos para abordar un problema o una situación particular propuesta por el sistema: juegos, modalidades, objetivos, etc. (insuficiente). 
10. Modelos par- Componentes del diseño de ticularesdeldi- juegos: fantasía, ambientes, seño de juegos competencia, curiosidad, etc. (adecuado).
Componentes del diseño de juegos: fantasía, ambientes, competencia, curiosidad, etc. (suficiente).
Componentes del diseño de juegos: fantasía, ambientes, competencia, curiosidad, etc. (insuficiente).

Fuente: elaboración propia a partir de Colomba (2006) y Deterding et al. (2014).

Como se puede apreciar en el cuadro 7, las casillas con trama gris oscuro representan nuestra perspectiva de evaluación de la plataforma. En este caso, en lo que se refiriere a los elementos de usabilidad y ergonomía, desde nuestra perspectiva y uso, estimamos que la organización, la oferta de funciones, el tiempo de espera y la facilidad de aprendizaje resultan características suficientes para un uso correcto de las aplicaciones en Pear Deck. Sin embargo, estimamos también que la plataforma no es muy intuitiva y que las funciones no responden de manera fluida en todos los casos. Durante las pruebas realizadas en este estudio, tuvimos algunos problemas para abrir presentaciones y generar contenidos. En ciertas ocasiones los tiempos de espera fueron muy largos y el sistema falló varias veces.

Por otra parte, en lo que s e refiere al impacto en los niveles y en los patrones de juego, creemos que la plataforma puede ser utilizada para crear diferentes actividades lúdicas que deberán ser construidas y diseñadas por el profesor. No obstante, las funciones disponibles en Pear Deck no ofrecen por sí mismas dinámicas y mecánicas propias de gamificación. El docente deberá diseñar sus contenidos para generar las dinámicas y así crear un entorno más lúdico concebido por él mismo y no por los medios ofrecidos por la aplicación.

\subsection{Classcraft}

\subsubsection{Descripción general}

Classcraft es una plataforma de gestión de comportamiento que destaca por sus características visuales relativas a la inclusión de elementos del juego de rol en el aula. Mediante un sitio web y una aplicación móvil, el profesor puede gestionar componentes de comportamiento entre sus alumnos. Para hacer uso de sus características es imprescindible crear una cuenta en el sitio <https://www.classcraft.com/es/>, donde el usuario puede elegir entre los tipos profesor, estudiante y padre. Cabe mencionar que se puede hacer uso de las funciones mediante el ingreso con una cuenta de Google. 
La plataforma Classcraft permite crear un ambiente de aprendizaje basado en la gestión de personajes en un entorno de tipo medieval en el que el estudiante podrá elegir entre tres clases de héroes: mago, guerrero y curandero (véase figura 4).
Classcraft permite crear un ambiente de aprendizaje basado en la gestión de personajes en un entorno de tipo medieval en el que el estudiante podrá elegir entre tres clases de héroes

Figura 4. Tipos de personajes que se pueden elegir

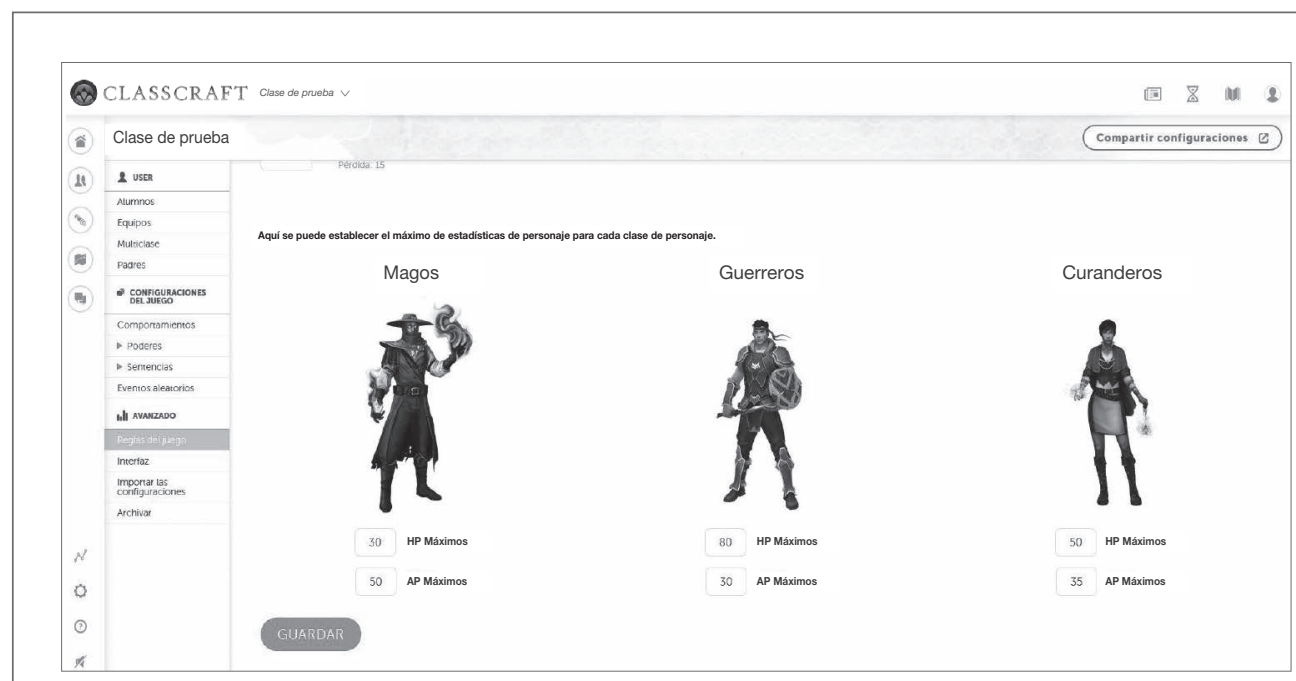

Fuente: elaboración propia.

Cada personaje cuenta con unas características propias que le permitirán realizar acciones en función de las reglas del curso (establecidas por el profesor); por ejemplo, un mago podría tener el poder de salir dos minutos antes de clase, pero dispone solo de 30 puntos de salud que podrían verse afectados al no cumplir con criterios de comportamiento en clase. Así, si el profesor decide quitar 10 puntos de salud por llegar tarde y el estudiante (mago) no tiene más puntos, este se verá obligado a cumplir con una tarea extra para que su personaje pueda revivir.

Resulta importante comentar que las reglas de comportamiento pueden ser editadas por el profesor para ajustarse a las necesidades del ambiente de aprendizaje, por lo que depende de esta situación que las mecánicas y los componentes se ajusten de manera equilibrada, considerando también que se requiere una explicación previa de las dinámicas de la plataforma y su impacto en los contenidos educativos. 
Por otra parte, la plataforma permite crear equipos con los usuarios y dispone de herramientas que podrían ayudar a gestionar ciertas actividades; por ejemplo, La Rueda del Destino, aplicación para seleccionar estudiantes al azar, y Los Jinetes de Vay, para crear eventos aleatorios que afecten a los personajes (véase figura 5).

Figura 5. Herramientas extra de Classcraft

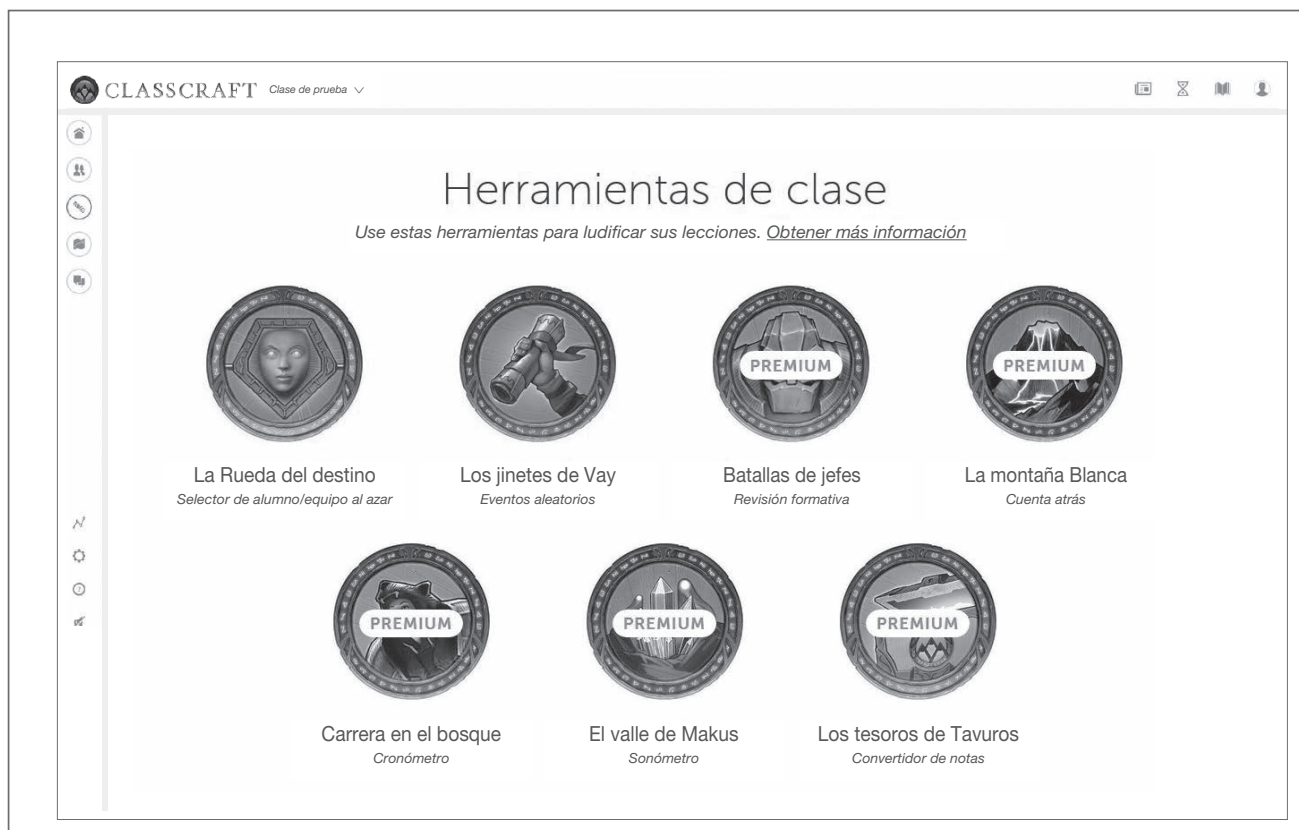

Fuente: elaboración propia.

Resulta importante comentar que, mediante el pago de una cuota mensual o anual, el gestor puede tener acceso a un mayor número de herramientas para enriquecer las actividades, los contenidos y las dinámicas de la plataforma; por ejemplo, acceso al cronómetro, a las batallas, a las notas y a las estadísticas. Además, con una membresía premium los estudiantes tienen la posibilidad de hacer uso de ciertos puntos (monedas de oro virtuales) para tener acceso a nuevas funciones, como comprar equipo o mascotas (véase figura 6).

\section{Mediante el pago de una cuota} mensual o anual, el gestor puede tener acceso a un mayor número de herramientas para enriquecer las actividades, los contenidos y las dinámicas de Classcraft; por ejemplo, acceso al cronómetro, a las batallas, a las notas y a las estadísticas 
Figura 6. Funciones extra de la cuenta premium en Classcraft

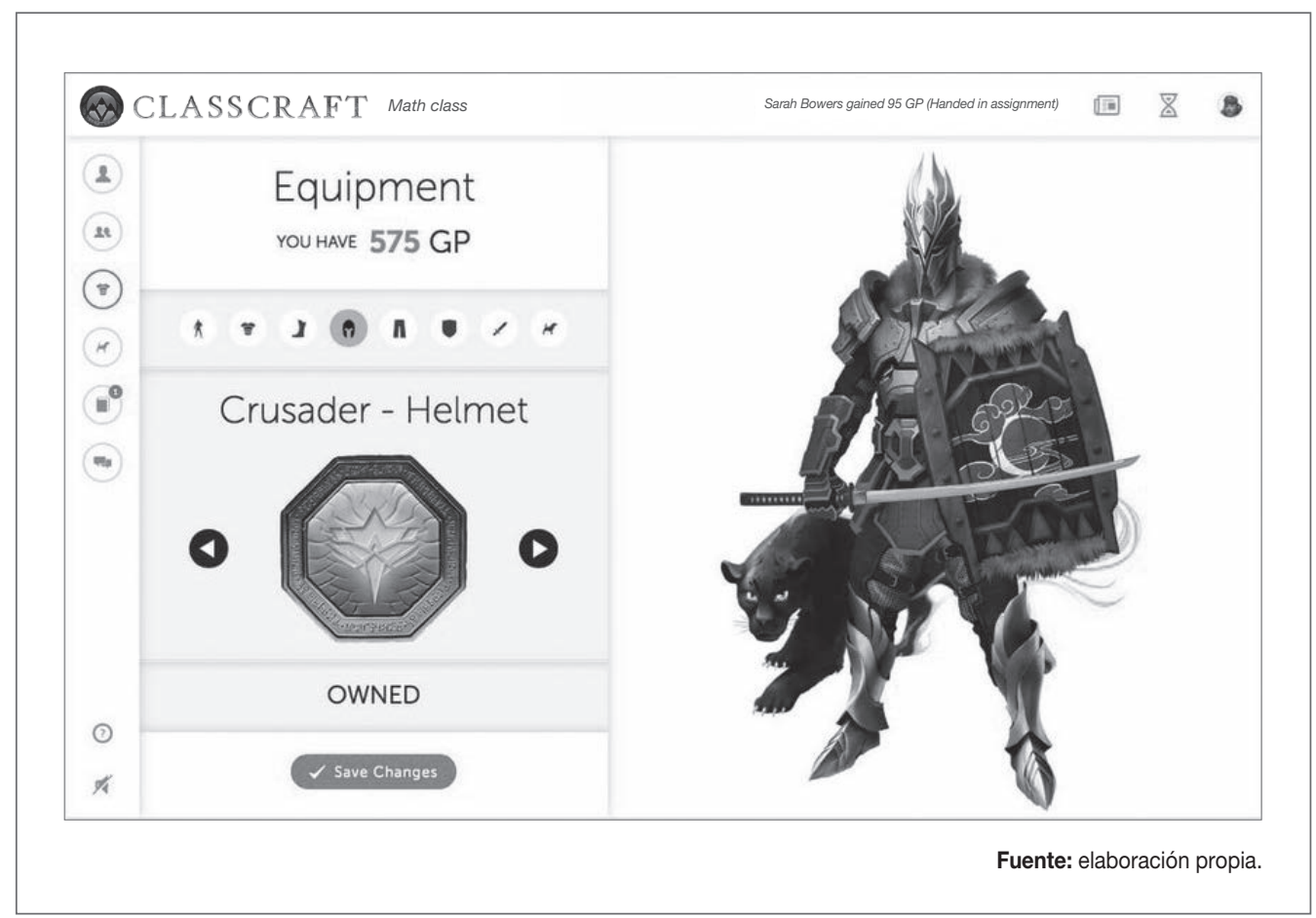

En resumen, Classcraft permite la gestión de un cierto número de actividades en un entorno digital que facilita la posibilidad de que los estudiantes entren al mundo de rol y hagan uso de su imaginación para decidir sobre las acciones de su personaje virtual en función de las reglas establecidas en un entorno educativo. De esta manera, el estudiante podría disponer de habilidades y poderes que le otorguen beneficios que resulten motivadores a la hora de tener un buen comportamiento en clase.

\subsubsection{Usos en gamificación}

En lo que se refiere a la gamificación, consideramos que Classcraft provee de un entorno lúdico interesante que permite a los estudiantes reflexionar sobre su comportamiento para obtener ciertas ventajas en clase. Mediante un sistema de progresión basado en la experiencia (puntos otorgados por el profesor), el alumno puede sentirse motivado para realizar las tareas encomendadas y así ganar nuevos poderes que le permitirán tener ciertos beneficios en la práctica real; por ejemplo, entregar una tarea más tarde o usar notas en el examen. Creemos que esta modalidad permite al profesor establecer un ambiente que incide de manera positiva en la motivación en el aula mediante la integración de elementos de la gamificación, como 
emociones, narración, relaciones, avatar, colaboración, recompensas, puntos, entre otros. Además, con el uso de la aplicación móvil, el estudiante puede estar al tanto del progreso de su personaje y de su equipo en el aula, por lo que el entorno digital puede integrarse completamente en el espacio físico para motivar la toma de decisiones conscientes, fundamentadas en las normas del curso.

\subsubsection{Limitaciones e inconvenientes}

Consideramos que Classcraft ofrece una perspectiva interesante que podría tener un impacto positivo en los procesos didácticos. No obstante, el uso continuo de una cuenta básica podría suponer un obstáculo (características limitadas que podrían volverse obsoletas en poco tiempo).

A partir de las pruebas realizadas con la versión gratuita, nos hemos percatado de que las herramientas disponibles podrían resultar pobres considerando el aspecto de motivación del estudiante, pues no se permite crear misiones en esta versión y el aspecto lúdico se limita a los comportamientos en la clase.

Consideramos que Classcraft podría ser positivo en el entorno lúdico, pero resultaría necesario incluir otras herramientas para subsanar sus carencias u optar por una cuenta premium para enriquecer el entorno y motivar a un mayor uso de las aplicaciones disponibles.

Por otro lado, es importante considerar que para un mejor uso de las herramientas de Classcraft se requiere que todos los participantes dispongan de un dispositivo móvil con acceso a internet, situación que podría complicar su integración en algunos centros educativos.

\subsubsection{Evaluación de las características de usabilidad web y gamificación}

En cuanto a la evaluación de la usabilidad web y la presencia de elementos lúdicos en la aplicación, de la misma manera que en la herramienta anterior, para el caso de Classcraft se utilizó la rúbrica de evaluación elaborada previamente.

En este caso, buscando la practicidad en la presentación de los resultados, hemos eliminado las descripciones de las escalas de evaluación para la usabilidad con el objetivo de reducir el tamaño de la tabla, pero estas pueden ser nuevamente consultadas en el cuadro 7 , donde se incluyen por primera vez. El cuadro 8 nos permite evidenciar el funcionamiento general y las funciones e implicación de la gamificación en el caso de Classcraft. 


\section{Cuadro 8. Evaluación de la usabilidad y de los patrones de juego de la experiencia con la herramienta Classcraft}

\begin{tabular}{|c|c|c|c|}
\hline Criterios & \multicolumn{3}{|c|}{ Escala de evaluación } \\
\hline 1. Aprendizaje & Familiaridad (adecuado). & Familiaridad (suficiente). & Familiaridad (insuficiente). \\
\hline 2. Operatividad & Manipulación (adecuada). & Manipulación (suficiente) & Manipulación (insuficiente). \\
\hline 3. Satisfacción & $\begin{array}{l}\text { Sensación de satisfacción } \\
\text { (adecuado). }\end{array}$ & $\begin{array}{l}\text { Sensación de satisfacción (su- } \\
\text { ficiente). }\end{array}$ & $\begin{array}{l}\text { Sensación de satisfacción (in- } \\
\text { suficiente). }\end{array}$ \\
\hline 4. Contenido & $\begin{array}{l}\text { Claridad en la organización y } \\
\text { presentación de contenidos } \\
\text { (adecuado). }\end{array}$ & $\begin{array}{l}\text { Claridad en la organización y } \\
\text { presentación de contenidos } \\
\text { (suficiente). }\end{array}$ & $\begin{array}{l}\text { Claridad en la organización y } \\
\text { presentación de contenidos } \\
\text { (insuficiente). }\end{array}$ \\
\hline 5. Eficiencia & $\begin{array}{l}\text { Tiempo de respuesta y nece- } \\
\text { sidad de ayudas (adecuado). }\end{array}$ & $\begin{array}{l}\text { Tiempo de respuesta y nece- } \\
\text { sidad de ayudas (suficiente). }\end{array}$ & $\begin{array}{l}\text { Tiempo de respuesta y nece- } \\
\text { sidad de ayudas (insuficiente). }\end{array}$ \\
\hline 6. Eficacia & $\begin{array}{l}\text { Percepción de recuperación } \\
\text { y prevención de errores (ade- } \\
\text { cuado). }\end{array}$ & $\begin{array}{l}\text { Percepción de recuperación } \\
\text { y prevención de errores (su- } \\
\text { ficiente). }\end{array}$ & $\begin{array}{l}\text { Percepción de recuperación y } \\
\text { prevención de errores (insufi- } \\
\text { ciente). }\end{array}$ \\
\hline $\begin{array}{l}\text { 7. Patrones de } \\
\text { concepción } \\
\text { de interfaces } \\
\text { de juego }\end{array}$ & $\begin{array}{l}\text { Presencia de elementos de } \\
\text { juego adaptados a un proble- } \\
\text { ma o contexto dado: medallas, } \\
\text { niveles y puntos (adecuado). }\end{array}$ & $\begin{array}{l}\text { Presencia de elementos de } \\
\text { juego adaptados a un proble- } \\
\text { ma o contexto dado: medallas, } \\
\text { niveles y puntos (suficiente). }\end{array}$ & $\begin{array}{l}\text { Presencia de elementos de } \\
\text { juego adaptados a un proble- } \\
\text { ma o contexto dado: medallas, } \\
\text { niveles y puntos (insuficiente). }\end{array}$ \\
\hline $\begin{array}{l}\text { 8. Patrones de } \\
\text { diseño de jue- } \\
\text { go y meca- } \\
\text { nismos }\end{array}$ & $\begin{array}{l}\text { Inclusión de elementos propios } \\
\text { del juego: límite de tiempo, re- } \\
\text { cursos limitados, turnos, etc. } \\
\text { (adecuado). }\end{array}$ & $\begin{array}{l}\text { Inclusión de elementos propios } \\
\text { del juego: límite de tiempo, re- } \\
\text { cursos limitados, turnos, etc. } \\
\text { (suficiente). }\end{array}$ & $\begin{array}{l}\text { Inclusión de elementos propios } \\
\text { del juego: límite de tiempo, re- } \\
\text { cursos limitados, turnos, etc. } \\
\text { (insuficiente). }\end{array}$ \\
\hline $\begin{array}{l}\text { 9. Principios y } \\
\text { heurística del } \\
\text { diseño }\end{array}$ & $\begin{array}{l}\text { Inclusión de elementos para } \\
\text { abordar un problema o una } \\
\text { situación particular propuesta } \\
\text { por el sistema: juegos, moda- } \\
\text { lidades, objetivos, etc. (ade- } \\
\text { cuado). }\end{array}$ & $\begin{array}{l}\text { Inclusión de elementos para } \\
\text { abordar un problema o una } \\
\text { situación particular propuesta } \\
\text { por el sistema: juegos, moda- } \\
\text { lidades, objetivos, etc. (sufi- } \\
\text { ciente). }\end{array}$ & $\begin{array}{l}\text { Inclusión de elementos para } \\
\text { abordar un problema o una } \\
\text { situación particular propuesta } \\
\text { por el sistema (juegos, moda- } \\
\text { lidades, objetivos, etc. (insufi- } \\
\text { ciente). }\end{array}$ \\
\hline $\begin{array}{l}\text { 10. Modelos par- } \\
\text { ticulares del di- } \\
\text { seño de juegos }\end{array}$ & $\begin{array}{l}\text { Componentes del diseño de } \\
\text { juegos: fantasía, ambientes, } \\
\text { competencia, curiosidad, etc. } \\
\text { (adecuado). }\end{array}$ & $\begin{array}{l}\text { Componentes del diseño de } \\
\text { juegos: fantasía, ambientes, } \\
\text { competencia, curiosidad, etc. } \\
\text { (suficiente). }\end{array}$ & $\begin{array}{l}\text { Componentes del diseño de } \\
\text { juegos: fantasía, ambientes, } \\
\text { competencia, curiosidad, etc. } \\
\text { (insuficiente). }\end{array}$ \\
\hline
\end{tabular}

Fuente: elaboración propia a partir de Colomba (2006) y Deterding et al. (2014). 
Como se puede apreciar en el cuadro 8, las casillas con trama gris oscuro representan nuestra perspectiva de evaluación de la plataforma. A partir de los resultados arrojados por la evaluación, hemos podido constatar que Classcraft incide de manera positiva en la mayoría de los criterios de integración de patrones y principios de juego.

Como se puede apreciar en el cuadro 8 , hemos otorgado a la mayoría de las categorías la calificación de «Adecuado» considerando que la aplicación dispone de un gran número de posibilidades didácticas en lo que se refiere a la gamificación, ya que, al ser un sistema abierto, el profesor puede utilizar el ambiente completo adaptándolo a sus objetivos; por ejemplo, para la creación de premios y recompensas o en el establecimiento de los métodos para que el estudiante genere puntos y experiencia. La plataforma Classcraft ofrece desde su primer registro un entorno lúdico que resulta curioso, incluso para el profesor, debido a su aspecto fantástico, apoyado por los ejemplos que esta ofrece. Cabe recordar que esta evaluación fue realizada a partir de la versión gratuita y quizás, con la versión de paga, se puedan incrementar en mayor medida las posibilidades didácticas de la plataforma. Es importante destacar los resultados que ha tenido esta aplicación en los contextos didácticos. Para ello, destacamos los trabajos realizados por Janiec (2015), quien ha logrado experiencias significativas en cuanto al uso de esta aplicación para el desarrollo de competencias de diplomacia, autogestión, trabajo colaborativo, toma de decisiones, entre otras.

Por otra parte, en relación con el funcionamiento y la usabilidad web, otorgamos una calificación de «Adecuado» para los criterios de «Operatividad», «Contenido» $y$ «Eficiencia». Desde nuestra perspectiva, Classcraft es una plataforma rápida, de libre manipulación y con información clara que permite que las diferentes opciones puedan ser comprendidas rápidamente. Sin embargo, en los apartados de «Aprendizaje», «Satisfacción» y «Eficacia», le hemos otorgado una calificación de «Suficiente». Aunque no se presentaron inconvenientes graves durante las pruebas, estimamos que los docentes necesitarán tiempo de práctica para aprender a utilizar el sitio web. Además, el hecho de que existan muchas opciones, botones y gráficos podría complicar la interacción entre el usuario y el sistema. Durante el uso de las diferentes herramientas del sitio, se ha percibido poca claridad sobre el funcionamiento, por lo que el usuario se podría equivocar antes de comprender la respuesta o la acción que ofrecen las diferentes opciones.

\subsection{Quizizz}

\subsubsection{Descripción general}

Quizizz es un sistema de gestión y creación de quizzes en línea que permite agregar elementos lúdicos transformando el ambiente de revisión de contenidos en una interfaz que agrega sonido, 
tiempo e imágenes con el propósito de motivar a los estudiantes en la realización de pruebas en la clase. Esta plataforma tiene una gran similitud con la herramienta Kahoot!, pero se distingue por permitir a los creadores agregar en la retroalimentación (después de cada pregunta) imágenes de tipo meme (construcción multimedia de mensajes), término utilizado en la última década en medios digitales. Para poder ingresar a la plataforma se requiere un registro previo que implica la utilización de correo y contraseña para el acceso a las diferentes funciones; sin embargo, Quizizz posibilita su ingreso mediante una cuenta de Google sin necesidad de registro.

El sistema ofrece una interfaz que podría considerarse simple, con un espacio central de búsqueda de pruebas y una columna lateral izquierda con las funciones de creación y gestión. En el proceso de creación de las pruebas el docente podrá seleccionar un título, añadir una imagen de presentación y elegir preguntas de la base de datos o crear dos tipos de preguntas: con una sola respuesta correcta o con opción múltiple (véase figura 7).

Figura 7. Creación de preguntas en Quizizz

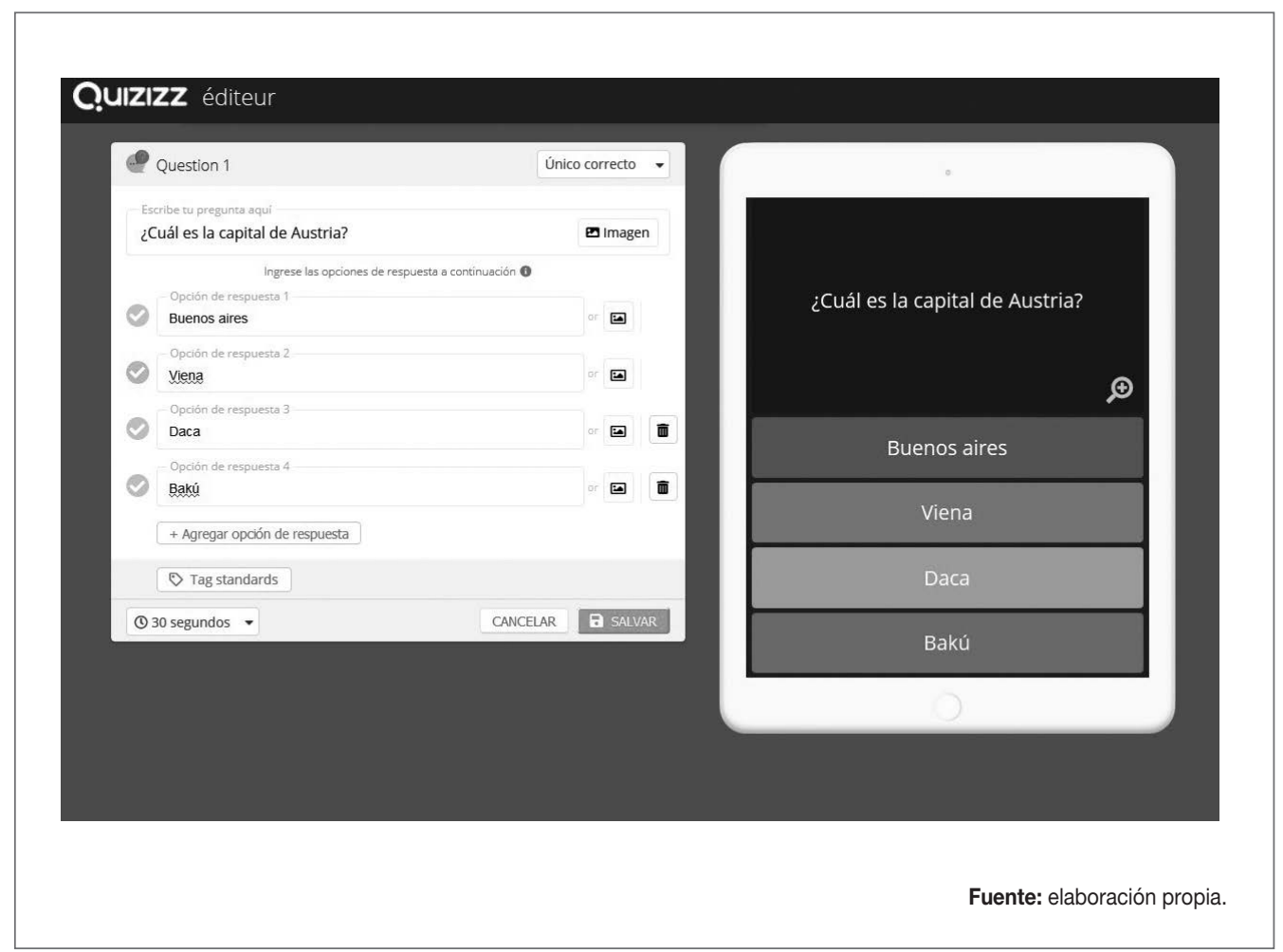

Asimismo, el docente puede agregar imágenes a las respuestas o a la pregunta, ya sea para ilustrar la información o adornar la presentación. Además, se puede añadir tiempo de 
respuesta a cada pregunta. Para la realización de las pruebas en clase, el estudiante tendrá que insertar un código (proporcionado por el profesor) con el que podrá entrar en la prueba y responder a las preguntas en su dispositivo digital, donde deberá seleccionar la respuesta correcta mediante recuadros de colores, que nosotros reproducimos en blanco y negro (véase figura 8).

Figura 8. Interfaz de selección de respuestas

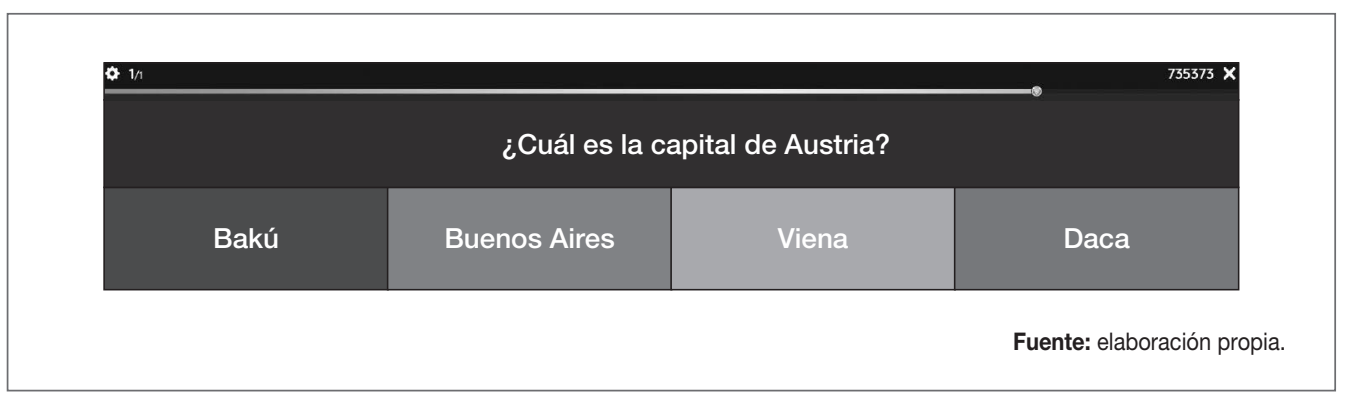

En la pantalla del profesor, este puede ver el tiempo disponible para cada pregunta y las ac ciones de todos los estudiantes participantes. El estudiante, en su pantalla, puede ver el tiempo, las preguntas, las insignias y los resultados de las respuestas de la prueba. En relación con las modalidades de la prueba, el profesor tiene la posibilidad de utilizar el quiz como medio lúdico en el aula (juego de preguntas) o asignarlo como tarea. En ambos casos se tiene un registro final de los resultados y se dispone de un menú de opciones que permite establecer las opciones y reglas previas de las preguntas (véase figura 9).

Un elemento característico de Quizizz, además de sus rasgos lúdicos, es la posibilidad de agregar en la retroalimentación de cada pregunta una imagen de tipo meme. Esto
Figura 9. Opciones para la prueba en Quizizz

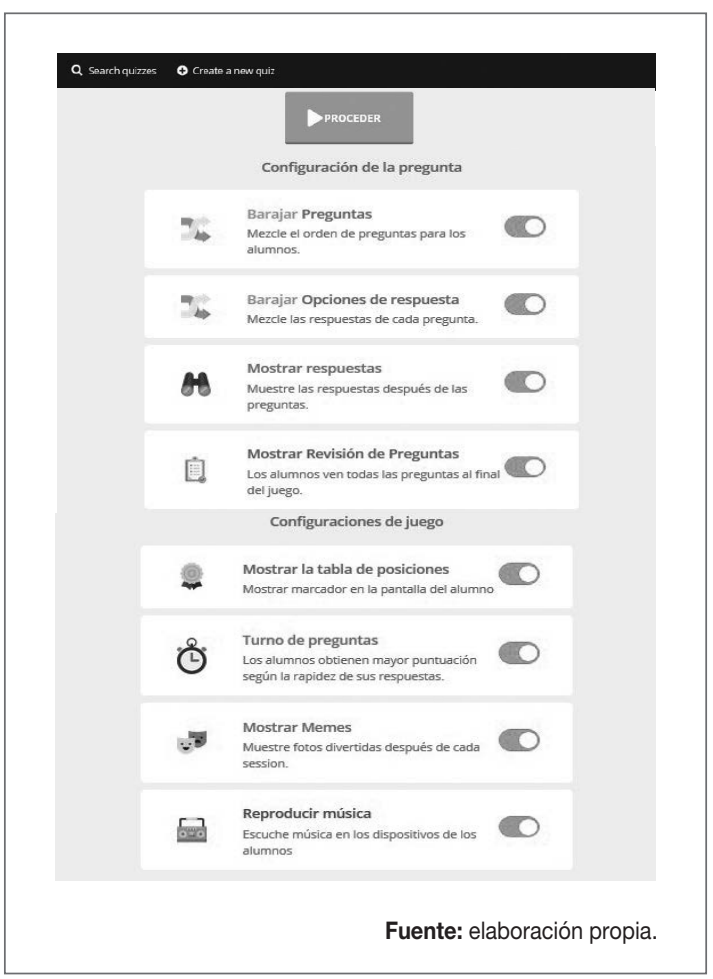


podría servir para darle un aspecto novedoso al tener en cuenta aquello que está de moda en materia de tecnología. El profesor puede seleccionar imágenes guardadas en el sitio o subir un archivo desde su ordenador y así agregar algún mensaje gracioso para crear conjuntos de memes e integrarlos posteriormente a las pruebas en las modalidades mencionadas (véase figura 10).

Figura 10. Diseño de memes en Quizizz

\section{Q search quizzes $\odot$ create a new quiz}

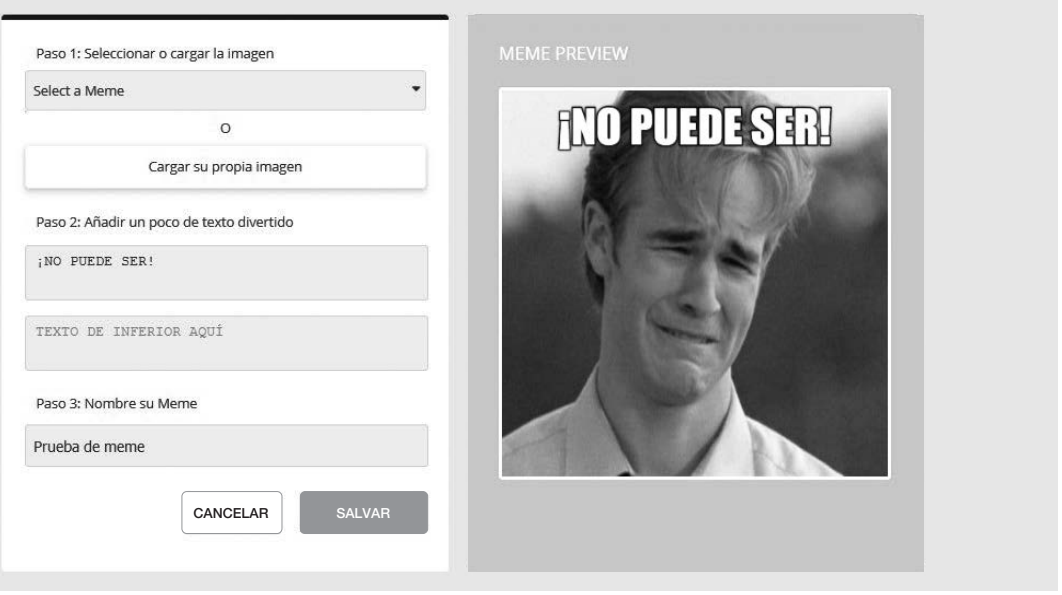

Fuente: elaboración propia.

\subsubsection{Usos en gamificación}

En lo que se refiere a las características de gamificación de Quizizz, esta plataforma ofrece la posibilidad de llevar al aula una actividad de tipo concurso mediante una interfaz lúdica, rápida y, posiblemente, interesante para los alumnos. Mediante la participación integral del grupo, los estudiantes pueden rivalizar entre ellos midiendo sus habilidades de velocidad de respuesta y de comprensión de contenidos con tiempos establecidos en una dinámica de competencia. Este tipo de actividades permite al profesor diversificar los recursos didácticos ofreciendo mayor variedad de ejercicios lúdicos que permitan romper con esquemas de evaluación o revisión preestablecidos. Consideramos que Quizizz incide de manera positiva en las dinámicas de juego mediante la integración de la competitividad, la frustración y las interacciones sociales con la modalidad de concurso en el aula. Además, la plataforma, en relación con las mecánicas de gamificación, ofrece la posibilidad de agre- 
gar aspectos creativos del profesor que impliquen la colaboración en clase, la entrega de recompensas y la retroalimentación en las pruebas realizadas.

\subsubsection{Limitaciones e inconvenientes}

Entre los inconvenientes y las limitaciones de Quizizz, podemos destacar, como en los casos anteriores, que para hacer uso de sus funciones completas es necesario un equipo informático en el aula por cada estudiante para que cada alumno pueda visualizar las preguntas de manera individual. Sin embargo, la falta de dispositivos informáticos para todos los estudiantes podría ser subsanado mediante la creación de grupos de trabajo. En relación con la creación de preguntas, consideramos que la plataforma limita en cierta medida las posibilidades de evaluación docente, ofreciendo solo dos tipos de preguntas. Pensamos que esta situación podría limitar la evaluación a contenidos más teóricos que prácticos, por lo que estimamos que esta plataforma debería ser utilizada como complemento para solo ciertas evaluaciones y no para todas las actividades que impliquen la revisión de conocimientos o competencias.

\subsubsection{Evaluación de las características de usabilidad web y gamificación}

Siguiendo con el proceso metodológico de este trabajo, hemos procedido a evaluar las características y las funciones de las herramientas de Quizizz con la ayuda del referente de evaluación generado previamente. Como en el caso de Classcraft, con la finalidad de mejorar la lectura y comprensión de este epígrafe, hemos eliminado del cuadro las descripciones de la escala de evaluación para los criterios de usabilidad web. Reiteramos que el lector puede ver las descripciones de la escala de evaluación en el cuadro 7 . El cuadro 9 muestra la incidencia de los patrones de diseño de juego de Quizizz, así como la evaluación de la usabilidad para el diseño web de interfaces digitales.

Cuadro 9. Evaluación de la usabilidad y de los patrones de juego de la experiencia con la herramienta Quizizz

\begin{tabular}{|c|c|c|c|}
\hline Criterios & \multicolumn{3}{|c|}{ Escala de evaluación } \\
\hline 1. Aprendizaje & Familiaridad (adecuado). & Familiaridad (suficiente). & Familiaridad (insuficiente). \\
\hline 2. Operatividad & Manipulación (adecuado). & Manipulación (suficiente). & Manipulación (insuficiente). \\
\hline 3. Satisfacción & $\begin{array}{l}\text { Sensación de satisfacción } \\
\text { (adecuado). }\end{array}$ & $\begin{array}{l}\text { Sensación de satisfacción (su- } \\
\text { ficiente). }\end{array}$ & $\begin{array}{l}\text { Sensación de satisfacción (in- } \\
\text { suficiente). }\end{array}$ \\
\hline
\end{tabular}




\begin{tabular}{|c|c|c|c|}
\hline Criterios & \multicolumn{3}{|c|}{ Escala de evaluación } \\
\hline 4. Contenido & $\begin{array}{l}\text { Claridad en la organización y } \\
\text { presentación de contenidos } \\
\text { (adecuado). }\end{array}$ & $\begin{array}{l}\text { Claridad en la organización y } \\
\text { presentación de contenidos } \\
\text { (suficiente). }\end{array}$ & $\begin{array}{l}\text { Claridad en la organización y } \\
\text { presentación de contenidos } \\
\text { (insuficiente). }\end{array}$ \\
\hline 5. Eficiencia & $\begin{array}{l}\text { Tiempo de respuesta y nece- } \\
\text { sidad de ayudas (adecuado). }\end{array}$ & $\begin{array}{l}\text { Tiempo de respuesta y nece- } \\
\text { sidad de ayudas (suficiente). }\end{array}$ & $\begin{array}{l}\text { Tiempo de respuesta y nece- } \\
\text { sidad de ayudas (insuficiente). }\end{array}$ \\
\hline 6. Eficacia & $\begin{array}{l}\text { Percepción de recuperación } \\
\text { y prevención de errores (ade- } \\
\text { cuado). }\end{array}$ & $\begin{array}{l}\text { Percepción de recuperación } \\
\text { y prevención de errores (su- } \\
\text { ficiente). }\end{array}$ & $\begin{array}{l}\text { Percepción de recuperación y } \\
\text { prevención de errores (insufi- } \\
\text { ciente). }\end{array}$ \\
\hline $\begin{array}{l}\text { 7. Patrones de } \\
\text { concepción } \\
\text { de interfaces } \\
\text { de juego }\end{array}$ & $\begin{array}{l}\text { Presencia de elementos de } \\
\text { juego adaptados a un proble- } \\
\text { ma o contexto dado: medallas, } \\
\text { niveles y puntos (adecuado). }\end{array}$ & $\begin{array}{l}\text { Presencia de elementos de } \\
\text { juego adaptados a un proble- } \\
\text { ma o contexto dado: medallas, } \\
\text { niveles y puntos (suficiente). }\end{array}$ & $\begin{array}{l}\text { Presencia de elementos de } \\
\text { juego adaptados a un proble- } \\
\text { ma o contexto dado: medallas, } \\
\text { niveles y puntos (insuficiente). }\end{array}$ \\
\hline $\begin{array}{l}\text { 8. Patrones de } \\
\text { diseño de jue- } \\
\text { go y meca- } \\
\text { nismos }\end{array}$ & $\begin{array}{l}\text { Inclusión de elementos propios } \\
\text { del juego: límite de tiempo, re- } \\
\text { cursos limitados, turnos, etc. } \\
\text { (adecuado). }\end{array}$ & $\begin{array}{l}\text { Inclusión de elementos propios } \\
\text { del juego: límite de tiempo, re- } \\
\text { cursos limitados, turnos, etc. } \\
\text { (suficiente). }\end{array}$ & $\begin{array}{l}\text { Inclusión de elementos propios } \\
\text { del juego: límite de tiempo, re- } \\
\text { cursos limitados, turnos, etc. } \\
\text { (insuficiente). }\end{array}$ \\
\hline $\begin{array}{l}\text { 9. Principios y } \\
\text { heurística del } \\
\text { diseño }\end{array}$ & $\begin{array}{l}\text { Inclusión de elementos para } \\
\text { abordar un problema o una si- } \\
\text { tuación particular propuesta por } \\
\text { el sistema: juegos, modalida- } \\
\text { des, objetivos, etc. (adecuado). }\end{array}$ & $\begin{array}{l}\text { Inclusión de elementos para } \\
\text { abordar un problema o una si- } \\
\text { tuación particular propuesta por } \\
\text { el sistema: juegos, modalida- } \\
\text { des, objetivos, etc. (suficiente). }\end{array}$ & $\begin{array}{l}\text { Inclusión de elementos para } \\
\text { abordar un problema o una si- } \\
\text { tuación particular propuesta por } \\
\text { el sistema: juegos, modalida- } \\
\text { des, objetivos, etc. (insuficiente). }\end{array}$ \\
\hline $\begin{array}{l}\text { 10. Modelos par- } \\
\text { ticulares del di- } \\
\text { seño de juegos }\end{array}$ & $\begin{array}{l}\text { Componentes del diseño de } \\
\text { juegos: fantasía, ambientes, } \\
\text { competencia, curiosidad, etc. } \\
\text { (adecuado). }\end{array}$ & $\begin{array}{l}\text { Componentes del diseño de } \\
\text { juegos: fantasía, ambientes, } \\
\text { competencia, curiosidad, etc. } \\
\text { (suficiente). }\end{array}$ & $\begin{array}{l}\text { Componentes del diseño de } \\
\text { juegos: fantasía, ambientes, } \\
\text { competencia, curiosidad, etc. } \\
\text { (insuficiente). }\end{array}$ \\
\hline
\end{tabular}

Fuente: elaboración propia a partir de Colomba (2006) y Deterding et al. (2014).

Como se puede apreciar en el cuadro 9, las casillas con trama gris oscuro representan nuestra perspectiva de evaluación de la plataforma. De los resultados obtenidos en la rúbrica de evaluación para la aplicación Quizizz, podemos afirmar que esta herramienta, en lo que se refiere a «Aprendizaje» de funciones, «Satisfacción» de respuestas y «Eficiencia» de las interacciones, se destaca por un funcionamiento «Adecuado». La aplicación Quizizz ofrece ayudas durante la creación de los quizzes, y la distribución de los elementos multimedia y el contenido resultan fáciles de aprender desde la

La aplicación Quizizz ofrece ayudas durante la creación de los quizzes, y la distribución de los elementos multimedia y el contenido resultan fáciles de aprender desde la primera manipulación del sitio web 
primera manipulación del sitio web. Aunque el aspecto de libertad en la manipulación de las funciones es algo limitado, consideramos que Quizizz cumple positivamente con las necesidades tecnológicas actuales en lo referente a ergonomía y usabilidad en entornos digitales.

En cuanto a la inclusión de patrones de diseño de juegos, la herramienta en cuestión permite incidir de manera positiva en la mayoría de los aspectos didácticos y lúdicos de la gamificación. Por ejemplo, durante la realización de un quiz, el estudiante se encuentra en un ambiente de competencia en el que se da un tiempo limitado, se asignan puntos por respuesta, se presentan turnos y se dan clasificaciones al final de la prueba, de tal manera que se ponen en práctica los elementos de juego evaluados en nuestra rúbrica en relación con los criterios 7, 8 y 10 (véase cuadro 9). En cuanto al apartado lúdico, creemos que uno de los aspectos que podría ser mejorado es la ampliación de las funcionalidades en lo que se refiere a las posibilidades didácticas y alternativas de actividades, ya que el sistema es un poco cerrado en cuanto a los tipos de preguntas posibles y a las diferentes modalidades de juego. Sin embargo, gracias al aspecto lúdico de competencia de Quizizz, las dinámicas de revisión pueden ser más interesantes y atractivas para el estudiante. En relación con esta perspectiva, nos parece pertinente rescatar los trabajos de Martínez-Martínez (2018) y Zhao (2019), quienes observaron un incremento de la motivación y una opinión favorable del estudiante en cuanto a su integración en la clase.

\section{Conclusiones}

El presente estudio nos ha permitido detectar y clasificar un número considerable de herramientas tecnológicas enfocadas a los procesos de gamificación en clase. Mediante una indagación no exhaustiva en el buscador Google hemos logrado detectar 23 aplicaciones disponibles que podrían integrarse en un ambiente lúdico de aprendizaje. Además, hemos realizado una revisión general de las diferentes herramientas resultantes con el propósito de clasificarlas teniendo en cuenta sus funciones y su área de aplicación. Consideramos que los resultados de esta investigación permiten a los académicos interesados en este campo ampliar el espectro sobre la disponibilidad tecnológica en la materia a fin de localizar los instrumentos que permitan enriquecer los ambientes lúdicos de enseñanza. No obstante, estimamos que este estudio es solo una pequeña contribución, pues la variedad de instrumentos tecnológicos disponibles en la actualidad es inmensa y podría resultar interesante continuar con las investigaciones.

Por otra parte, el trabajo de análisis realizado nos ha permitido esclarecer las funciones principales de tres herramientas aplicables a la gamificación. A partir de una descripción cualitativa concluimos que estas aplicaciones tecnológicas podrían complementarse en un entorno educativo. Los docentes pueden hacer uso de Classcraft para crear un ambiente que integre emociones, narración y roles para gestionar los comportamientos; el uso de Pear Deck con su interfaz interactiva podría enfocarse en la parte teórica en clase; y Quizizz, en la parte de evaluación de evidencias de aprendizaje. Así, las tres herramientas sirven de apoyo en la 
construcción del ambiente y de la progresión lúdica, con la posibilidad de incluir y adaptar otros recursos didácticos o instrumentos tecnológicos que permitan enriquecer las dinámicas, las mecánicas y los componentes de gamificación, considerando los elementos que faltan.

Entre los inconvenientes detectados se encuentra la necesidad constante de que en las aulas existan dispositivos informáticos, situación que en algunos casos podría complicar la integración de la gamificación con medios digitales.

Gracias a los cuadros descriptivos que muestran la implicación de las herramientas en la gamificación (véanse cuadros $3,4,5$ y 6) y a aquellos que evalúan aspectos de usabilidad y de patrones de juego (véanse cuadros 7, 8 y 9), concluimos que para construir un ambiente que tenga en cuenta la mayoría de los elementos de esta perspectiva se requiere hacer uso de diferentes medios tecnológicos o recursos educativos, pues el uso de un único recurso lúdico no siempre implica un desarrollo complejo de la enseñanza-aprendizaje bajo el enfoque educativo aludido.

Finalmente, estimamos que este trabajo permite contribuir a la comprensión de los procesos de gamificación gracias al análisis de los recursos tecnológicos estudiados, pues las diferentes funciones encontradas permiten ilustrar en cierta medida este enfoque en contextos digitales. Además, los profesores y académicos interesados en el ámbito podrían resultar beneficiados con la información expuesta, ya que les ayudará a ubicar de manera más precisa algunas herramientas tecnológicas aplicables a la gamificación para su integración en el aula o para su estudio en diferentes ámbitos. De esta manera, consideramos que este trabajo representa una pequeña contribución a este enfoque educativo y que aún existe un gran campo de estudio sobre esta materia.

\section{Referencias bibliográficas}

Alejaldre Biel, L. y García Jiménez, A. M. a . (2015). Gamificar: el uso de los elementos del juego en la enseñanza del español. Actas del $L$ Congreso Internacional de la Asociación Europea de Profesores de Español. Recuperado de <https://cvc.cervantes.es/ense nanza/biblioteca_ele/aepe/congreso_50. htm> (consultado el 5 de noviembre de 2018).

Aznar-Díaz, I., Raso-Sánchez, F., Hinojo-Lucena, A. y Romero-Díaz de la Guardia, J. (2017). Percepciones de los futuros docentes res- pecto al potencial de la ludificación y la inclusión de los videojuegos en los procesos de enseñanza-aprendizaje. EDUCAR, 54(2), 11-28. Recuperado de <http://dx.doi.org/ 10.5565/rev/educar.840> (consultado el 10 de septiembre de 2018).

Balasubramanian, K., Jaykumar, V. y Nitin, L. (2014). A study on «Student preference towards the use of Edmodo as a learning platform to create responsible learning environment». Social and Behavioral Sciences, 144, 416-422. 
Baldeón, J., Rodríguez, I., Puig, A. y LópezSánchez, M. (2017). Evaluación y rediseño de una experiencia de gamificación en el aula basada en estilos de aprendizaje y tipos de jugador. En R. Contreras y J. Eguia, J. (Eds.), Experiencias de gamificación en aulas (pp. 95-111). Barcelona: InCom-UAB Publicacions, 15.

Caponetto, I., Earp, J. y Ott, M.(2014). Gamification and education: a literature review. En C. Busch (Ed.), 8th European Conference on Games-Based Learning. ECGBL 2014 (pp. 50-57). Vol. 1.

Carrión Candel, E. (2018). El uso de la gamificación y los recursos digitales en el aprendizaje de las ciencias sociales en la educación superior. DIM: Didáctica, Innovación y Multimedia, 36.

Colomba, N. (2006). Lineamientos de diseño para el desarrollo de aplicaciones usables bajo entornos web. Recuperado de <http:// artemisa.unicauca.edu.co/ iclaros/usabi lidad/chapter3.htm> (consultado el 2 de abril de 2019).

Contreras Espinosa, R. (2016). Juegos digitales y gamificación aplicados en el ámbito de la educación. Revista Iberoamericana de Educación a Distancia, 19(2), 27-33.

Contreras Espinosa, R. (2017). Gamificación en escenarios educativos. Revisando literatura para aclarar conceptos. En R. Contreras y Eguia, J. (Eds.), Experiencias de gamificación en aulas (pp. 11-17). BarceIona: InCom-UAB Publicacions, 15.

Corchuelo-Rodríguez, C. (2018). Gamificación en educación superior: experiencia innovadora para motivar estudiantes y dinamizar contenidos en el aula. EDUTEC: Revista Electrónica de Tecnología Educativa, 63, 29-41. Recuperado de <https:// doi.org/10.21556/edutec.2018.63.927> (consultado el 13 de noviembre de 2018).

Deterding, S., Dixon, D., Khaled, R. y Nacke, L. (2014). Du game design au gamefulness: définir la gamification. Sciences du Jeu, 2 . doi: 10.4000/sdj.287.

Díaz Cruzado, J. y Troyano Rodríguez, Y. (2013). El potencial de la gamificación aplicado al ámbito educativo. III Jornadas de Innovación Docente. Innovación Educativa: Respuesta en Tiempos de Incertidumbre. España: Universidad de Sevilla. Recuperado de: <https:// idus.us.es/xmlui/handle/11441/59067> (consultado el 23 de octubre de 2018).

Foncubierta, J. y Rodríguez C. (2014). Didáctica de la gamificación en la clase de español. Madrid: Edinumen. Recuperado de: <https: //www.edinumen.es/spanish_challenge/ gamificacion_didactica.pdf> (consultado el 14 de noviembre de 2018).

Gallego Aguilar, A. y Ágredo Ramos, A. (2016). Implementando una metodología de gamificación para motivar la lectura y escritura en jóvenes universitarios. Revista KEPES, 14, 61-81. Recuperado de <http://kepes.ucal das.edu.co/downloads/Revista14_4.pdf> (consultado el 22 de octubre de 2018).

García, M. e Hijón Neira, R. (2017). Análisis para la gamificación de un curso de formación profesional. Revista Iberoamericana de Informática Educativa, 26, 46-60.

Hamari, J., Koivisto, J. y Sarsa, H. (2014). Does gamification work?-A literature review of empirical studies on gamification. 47th Hawaii International Conference on System Sciences (pp. 3.025-3034). doi: 10.1109/ HICSS.2014.377.

Janiec, J. (2015). Use of gamification in the IB history class and as a tool for form teacher. New empirical research and solutions. Edukacja, 1(7), 105-120.

Jerí Rodríguez, D. (2008). Buenas prácticas en el ámbito educativo y su orientación a la gestión del conocimiento. Educación, 17(32), 29-48.

Lozada-Ávila, C. y Betancur-Gómez, S. (2017). La gamificación en la educación superior: una revisión sistemática. Revista Ingenierías Universidad de Medellín, 16(31), 97-124. 
Martín, M. (2017). Aportaciones pedagógicas de las TIC a los estilos de aprendizaje. Tendencias Pedagógicas, 37, 91-104. Recuperado de <http://dx.doi.org/10.15366/ tp2017.30.005> (consultado el 25 de noviembre de 2018).

Martínez Martínez, N., Berenguer-Albadalejo, C., Cabedo Serna, L., Evangelio Llorca, R., López Richart, J. y Múrtula Lafuente, V. (2018). Aprender derecho jugando. Quizizz y su aplicación a la asignatura. Regulación jurídico-civil del turismo. En R. Roig-Vila (Ed.), El compromiso académico y social a través de la investigación e innovación educativas en la enseñanza superior (pp. 684-693). Barcelona: Octaedro.

Mathupayas, T. (2013). Social network system in classroom: antecedents of Edmodo ${ }^{\odot}$ adoption. Journal of e-Learning and Higher Education. doi: 10.5171/2013.657749.

Moreno Martínez, N., Leiva Olivencia, J. y Matas Terrón, A. (2016). Mobile learning, gamificación y realidad aumentada para la enseñanza-aprendizaje de idiomas. International Journal of Educational Research and Innovation, 6, 16-34.

Oliva, H. (2016) La gamificación como estrategia metodológica en el contexto educativo universitario. Realidad y Reflexión, 44, 29-47. Recuperado de <https://doi. org/10.5377/ryr.v44i0.3563> (consultado el 10 de septiembre de 2018).

Ortiz-Colón, A., Jordán, J. y Agredal, M. (2018). Gamificación en educación: una panorámica sobre el estado de la cuestión. Educação e Pesquisa, 44. Recuperado de <http://dx.doi.org/10.1590/s1678-463420 1844173773 > (consultado el 20 de noviembre de 2018).

Parente, D. (2016). Gamificación en la educación. En R. Contreras y J. Eguia (Eds.). Gamificación en aulas universitarias (pp. 11-21). Barcelona: InCom-UAB Publicacions, 15.
Pascual-Seva, N., Sebastiá-Frasquet, M. ${ }^{a}$ T., Esteve Sendra, C., Asensio-Cuesta S., BabiIoni Griñón, M. ${ }^{a}$ E., Palomares Figueres, M. ${ }^{a}$ T., ... y Vargas Colas, M. ${ }^{a}$ (2015). Tecnologías de la información y la comunicación (TICs) para la gamificación. Congreso InRed 2015. Valencia: Universitat Politècnica de València. Recuperado de <http://dx.doi. org/10.4995/INRED2015.2015.1594> (consultado el 10 de septiembre de 2018).

Pomata García, J. A. y Díaz Ayuga, J. M. (2017). TIC y gamificación en la enseñanza de español como lengua extranjera: situación y líneas de actuación para las universidades japonesas. Cuadernos CANELA, 28, 79-101.

Sánchez-Rivas, E. y Pareja-Prieto, D. (2015). La gamificación como estrategia pedagógica en el contexto escolar. En J. Ruiz-Palmero, J. Sánchez-Rodríguez y E. Sánchez-Rivas (Eds.), Innovaciones con tecnologías emergentes. Málaga: Universidad de Málaga.

Sierra Lledo, C. y Juste Martí, A. (2018). Herramientas TIC para la gamificación en el aula. Publicaciones Didácticas, 93, 534-537.

Villalustre Martínez, L. y Moral Pérez, E. del. (2015). Gamificación: estrategia para optimizar el proceso de aprendizaje y la adquisición de competencias en contextos universitarios. Digital Education Review, 27, 13-31.

Willging, P., Astudillo, G., Bast, S., Occelli, M., Castro, L. y Distel, J. (2017). Educación con tecnologías: la gamificación aplicada para el aprendizaje de la programación. XIX Workshop de Investigadores en Ciencias de la Computación (pp. 1.169-1.173). Buenos Aires: RedUNCl. Recuperado de <http:// sedici.unlp.edu.ar/handle/10915/62862> (consultado el 20 de octubre de 2018).

Zhao, F. (2019). Using Quizizz to integrate fun multiplayer activity in the accounting classroom. International Journal of Higher Education, 8(1), 37-43. 


\section{¿Qué nos diferencia de otras Universidades online?}

La Universidad a Distancia de Madrid, UDIMA, está diseñada para cubrir las necesidades de las personas del siglo XXI: profesionales que demandan una titulación universitaria reconocida oficialmente y de prestigio, adaptada a Europa y en contacto con el mundo de la empresa, y que facilite, además, una buena inserción laboral o mejore la que ya se posee.
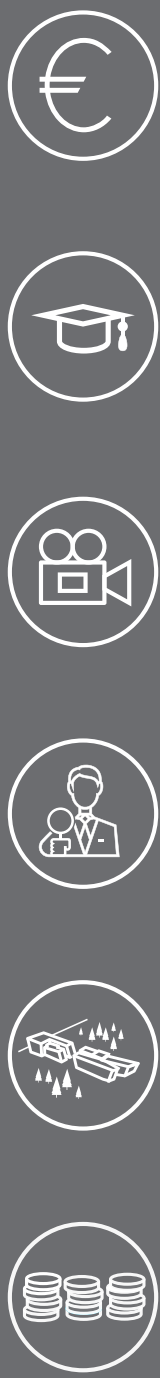

\section{Plató de grabación}

Contamos con un plató con las últimas tecnologías audiovisuales que nos permiten darte la máxima calidad en las clases en videoconferencia.

\section{Tutor personal}

Al inicio del Grado se te asignará un tutor personal que te acompañará todo el tiempo que estés con nosotros para que nunca te sientas solo.

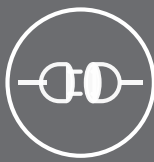

\section{Siempre conectados}

Nuestro compromiso es contestar en menos de $48 \mathrm{~h}$ a todas tus dudas, para que cumplir tus objetivos te sea más fácil. Siempre estaremos conectados.

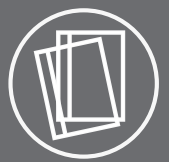

\section{Materiales adaptados}

Contamos con una Editorial propia que desarrolla los libros y carpetas especialmente diseñados para el aprendizaje online, que te llegarán a casa al principio de cada semestre.

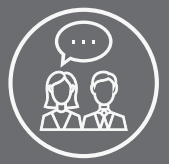

\section{Encuentros presenciales}

Realizamos talleres, conferencias y prácticas presenciales voluntarias que amplían el contenido de las asignaturas.

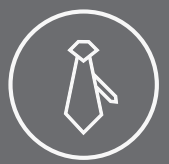

\section{Contacto con empresas}

Nuestra Bolsa de Trabajo y

Emprendedores te ofrece asesoría individualizada para que puedas potenciar tus cualidades y posicionarte como quieras en el mercado laboral.

\section{Campus propio}

Podrás venir a ver a los profesores a las instalaciones de Villalba. Nuestro campus ha ganado el prestigioso Premio Inmobiliario Internacional Asprima-SIMA.

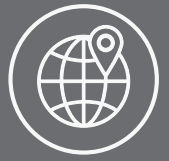

\section{Pago fraccionado}

Para que el dinero no sea un impedimento, te ofrecemos la posibilidad de realizar el pago fraccionado o a través de financiación bancaria. Que estudiar sea tu única preocupación.

\section{Sedes de examen}

Estamos cerca de ti. Además de alrededor de toda España, contamos con sedes en Europa, Asia y

América, con especial relevancia en Latinoamérica.

\section{Convocatoria en septiembre}

No es fácil compaginar el estudio con la vida personal y profesional. Por eso tenemos una convocatoria extra en septiembre. Tienes dos oportunidades al año de aprobar cada asignatura. 